\title{
Assessment of an ensemble seasonal streamflow forecasting system for Australia
}

\author{
James C. Bennett ${ }^{1,2}$, Quan J. Wang ${ }^{3}$, David E. Robertson ${ }^{1}$, Andrew Schepen ${ }^{4}$, Ming Li ${ }^{5}$, and Kelvin Michael ${ }^{2}$ \\ ${ }^{1}$ CSIRO Land \& Water, Clayton, Victoria, Australia \\ ${ }^{2}$ Institute for Marine and Antarctic Studies, University of Tasmania, Hobart, Tasmania, Australia \\ ${ }^{3}$ Department of Infrastructure Engineering, University of Melbourne, Parkville, Victoria, Australia \\ ${ }^{4}$ CSIRO Land \& Water, Dutton Park, Queensland, Australia \\ ${ }^{5}$ CSIRO Data61, Floreat, Western Australia, Australia
}

Correspondence to: James C. Bennett (james.bennett@csiro.au)

Received: 5 July 2017 - Discussion started: 7 July 2017

Revised: 8 October 2017 - Accepted: 29 October 2017 - Published: 30 November 2017

\begin{abstract}
Despite an increasing availability of skilful longrange streamflow forecasts, many water agencies still rely on simple resampled historical inflow sequences (stochastic scenarios) to plan operations over the coming year. We assess a recently developed forecasting system called "forecast guided stochastic scenarios" (FoGSS) as a skilful alternative to standard stochastic scenarios for the Australian continent. FoGSS uses climate forecasts from a coupled oceanland-atmosphere prediction system, post-processed with the method of calibration, bridging and merging. Ensemble rainfall forecasts force a monthly rainfall-runoff model, while a staged hydrological error model quantifies and propagates hydrological forecast uncertainty through forecast lead times. FoGSS is able to generate ensemble streamflow forecasts in the form of monthly time series to a 12-month forecast horizon.

FoGSS is tested on 63 Australian catchments that cover a wide range of climates, including 21 ephemeral rivers. In all perennial and many ephemeral catchments, FoGSS provides an effective alternative to resampled historical inflow sequences. FoGSS generally produces skilful forecasts at shorter lead times ( $<4$ months), and transits to climatologylike forecasts at longer lead times. Forecasts are generally reliable and unbiased. However, FoGSS does not perform well in very dry catchments (catchments that experience zero flows more than half the time in some months), sometimes producing strongly negative forecast skill and poor reliability. We attempt to improve forecasts through the use of (i) ESP rainfall forcings, (ii) different rainfall-runoff mod-
\end{abstract}

els, and (iii) a Bayesian prior to encourage the error model to return climatology forecasts in months when the rainfallrunoff model performs poorly. Of these, the use of the prior offers the clearest benefit in very dry catchments, where it moderates strongly negative forecast skill and reduces bias in some instances. However, the prior does not remedy poor reliability in very dry catchments.

Overall, FoGSS is an attractive alternative to historical inflow sequences in all but the driest catchments. We discuss ways in which forecast reliability in very dry catchments could be improved in future work.

\section{Introduction}

Recent years have seen a proliferation of experimental longrange ensemble streamflow forecasting systems (examples from this issue: Meißner et al., 2017; Beckers et al., 2016; Candogan Yossef et al., 2017; Bell et al., 2017; Greuell et al., 2016), and, to a lesser extent, the operationalization of these systems as forecasting services that are available to water agencies and the public. In Australia, the Bureau of Meteorology (the "Bureau") runs a freely available seasonal streamflow forecasting service that predicts total streamflow for the coming 3 months at more than 200 sites across Australia (www.bom.gov.au/water/ssf/). While the Bureau's service has been well received by Australian water agencies, a number of agencies still rely primarily on resampled historical inflow sequences, not forecasts, to plan operations for the 
coming year. Resampled historical inflow sequences (termed stochastic scenarios in this paper) have some appeal for water agencies: they are unbiased, they are available as time series, they are easy to generate to long time horizons, and, presuming a long observation record is available from which to sample, the ensemble of inflows is inherently statistically reliable (either taken at individual months or when individual ensemble members are summed, e.g. to produce an ensemble of 6 months' total inflow). The Bureau's service is based on a statistical method, the Bayesian joint probability (BJP) modelling approach (Wang and Robertson, 2011), which uses information from current streamflow conditions and climate indices to produce skilful streamflow forecasts. The BJP is able to produce skilful, unbiased forecasts with highly reliable ensembles, and can be used to generate monthly volume forecasts to short (e.g. 3 months) forecast horizons (Zhao et al., 2016). But the BJP is not well suited to generating time series forecasts to long (e.g. 12 months) time horizons, because it has no mechanism for simulating the shape of hydrographs over long lead times. Other seasonal forecasting systems generally have some combination of shortcomings with respect to stochastic scenarios: they may not produce reliable ensembles (e.g. Crochemore et al., 2016; Wood and Schaake, 2008); the ensembles may be biased with respect to climatology (e.g. Fundel et al., 2013; Wood and Schaake, 2008); and/or the forecasts may be less skilful than climatology for certain months or lead times (Yuan et al., 2013). Any of these can be a serious barrier to their use by water agencies to plan operations.

Of course, stochastic scenarios have a major shortcoming of their own: they take no account of information from current catchment and climate conditions, and thus offer no skill to water agencies. To combine the practical advantages of stochastic scenarios with useful information contained in forecasts, we recently proposed a new streamflow forecasting system called "forecast guided stochastic scenarios", or FoGSS. FoGSS uses post-processed climate forecasts from a coupled climate forecasting system to force a monthly rainfall-runoff model. A hydrological error model is then used to update forecasts, correct biases, and propagate forecast uncertainty through the lead times. FoGSS produces time series forecasts to long time horizons (12 months). As forecast skill declines with lead time, FoGSS is designed to nudge forecasts towards climatology. Each ensemble member in the forecast is a realistic 12-month hydrograph at a monthly time step. In a previous paper (Bennett et al., 2016), we described the theoretical underpinnings of FoGSS and showed that it performed well for two high-rainfall Australian catchments, producing skilful and reliable ensemble forecasts. We noted that the viability of FoGSS as a continent-wide forecasting system remained to be tested. In particular, FoGSS needs to be tested for ephemeral rivers, which are an important source of water (e.g. for agriculture) in many Australian regions. (Note that catchments that cease to flow are variously termed "intermittent" and "ephemeral" in other studies; we will refer to all rivers that cease to flow $>4 \%$ of the time as "ephemeral" in this paper.)

The aim of this paper is to test FoGSS on a wide range of Australian catchments that encompass different climatic and hydrologic conditions. We then vary components of the system - rainfall forcings, rainfall-runoff modelling, and the hydrological error model - to assess to what extent, if any, forecasts can be improved. The paper is structured as follows. We give an overview of the FoGSS model in Sect. 2, describe our set-up and data in Sect. 3, and describe our experiments to vary elements of FoGSS in Sect. 4. We present and discuss our results in Sect. 5, and we summarize and conclude our findings in Sect. 6.

\section{The FoGSS model}

A schematic of the FoGSS model is shown in Fig. 1.

\subsection{Ensemble rainfall forecasts}

Rainfall and sea-surface temperature (SST) predictions are taken from the POAMA M2.4 seasonal climate forecasting system (Hudson et al., 2013; Marshall et al., 2014). POAMA reforecasts are available as a 33-member ensemble comprised of 11 members each from three variants of the model; each variant has slightly different model physics. We use forecasts issued at the start of each calendar month (12 forecasts a year) from 1982 to 2010 . These forecasts are then post-processed with the method of calibration, bridging and merging (CBaM; Schepen and Wang, 2014; Schepen et al., 2014). While POAMA produces skilful rainfall forecasts in some months and seasons in parts of Australia, it suffers from deficiencies common to many dynamical climate forecasting models: forecasts are often biased at the scale of catchments; forecast ensembles tend to be overconfident; and forecasts may be substantially less skilful than climatology in certain months and seasons (Schepen et al., 2016).

We have shown elsewhere that it is only possible to correct all these deficiencies by calibration, rather than applying a simple bias-correction (Zhao et al., 2017). Accordingly, POAMA rainfall reforecasts are calibrated to each catchment with the BJP. This approach is effective at removing bias, correcting ensemble spread, and ensuring forecasts are "coherent" - that is, never less skilful than climatology forecasts (Hawthorne et al., 2013; Schepen et al., 2016; Peng et al., 2014). To maximize the skill of rainfall forecasts, we use "bridging" to build statistical relationships between POAMA forecasts of SST indices (e.g. Niño3.4) and catchment rainfall, again with the BJP. Bridging allows us to generate forecasts to 12-month forecast horizons: POAMA produces forecasts only to 9 months in advance; we use bridging to establish lagged relationships between 9-month SST forecasts and 10-, 11- and 12-month forecast horizons. To merge the calibration and bridging forecasts we use Bayesian model av- 


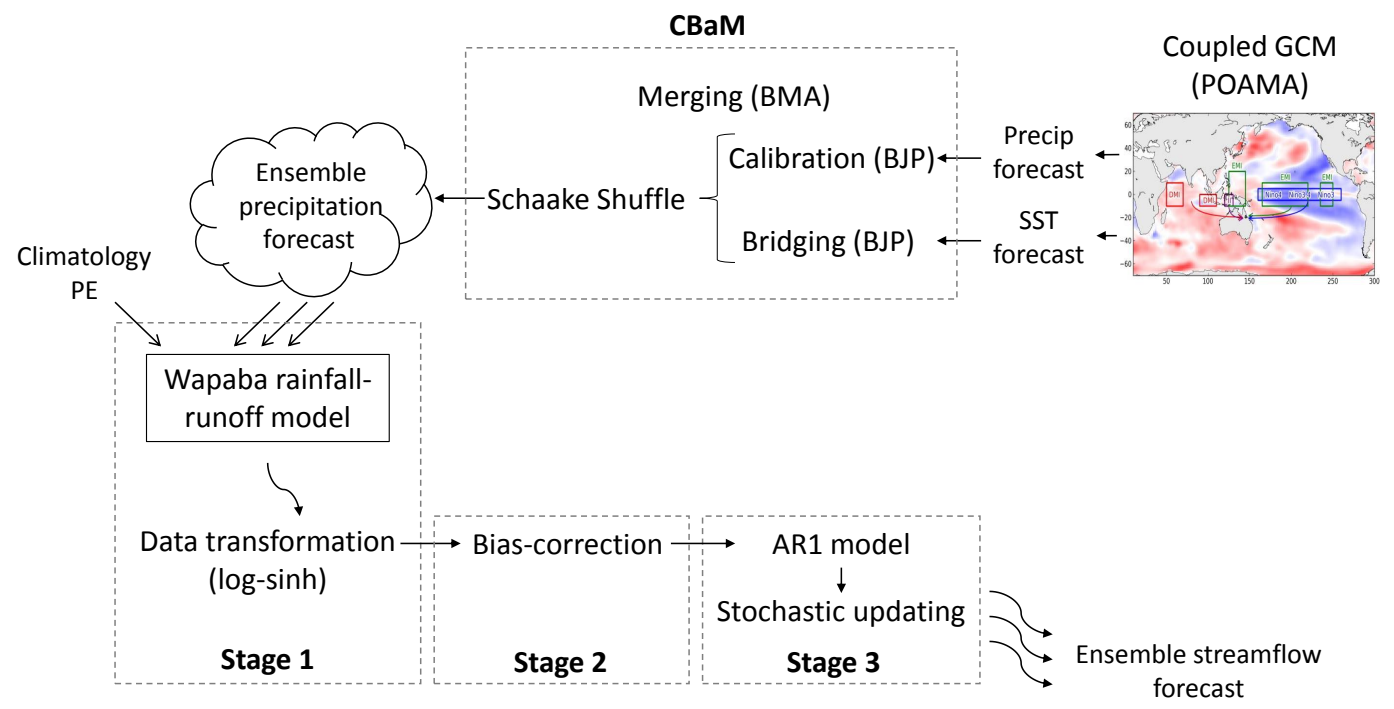

Figure 1. Schematic of the FoGSS model.

eraging (Wang et al., 2012a) to produce a forecast ensemble of 1000 members. Finally, realistic temporal patterns are instilled in each forecast ensemble member with the Schaake shuffle (Clark et al., 2004).

\subsection{Hydrological model}

Rainfall forecasts and climatology potential evaporation are used to force an initialized monthly rainfall-runoff model. In the original conception of FoGSS, we used the Wapaba model (Wang et al., 2011). In this study we also test two other rainfall-runoff models, GR2M and $\mathrm{ABCD}$, and we describe each rainfall-runoff model in Sect. 4.3.

\subsection{Error model}

Forcing a hydrological model with ensemble rainfall forecasts results in overconfident streamflow forecasts, as uncertainty in the hydrological model is not incorporated into the forecast. In addition, hydrological models, even when optimized, are usually subject to errors and bias. To address these issues, FoGSS employs a three-stage error model. The model is broken up into stages to avoid undesirable interaction between the error model parameters when they are estimated.

\subsubsection{Stage 1: data transformation}

We use the log-sinh transformation (Wang et al., 2012b) to normalize data and homogenize variance. The log-sinh transformation $(T F)$ is given by

$z=T F(q)=\frac{1}{b} \log (\sinh (a+b q))$ where $q$ is streamflow and $a$ and $b$ are parameters. For clarity, we will refer to the domain in which $q$ exists as the original domain to differentiate it from the transform domain of $z$.

\subsubsection{Stage 2: bias-correction}

Transformed streamflow is bias-corrected at each month $i=1,2, \ldots, 12=\operatorname{month}(t)$ by

$z_{2}(t)=d(i) z_{1}(t)+\mu(i)$,

where $z_{1}$ is the raw streamflow forecast after transformation with Eq. (1), and $d(i)$ and $\mu(i)$ are parameters.

An important feature of Eq. (2) is that $d$ can go to zero. That is, in months where the hydrological simulation performs poorly, the error model can return $z_{2} \approx \mu$, a constant akin to a climatology. As we shall see, this is a particularly important property in ephemeral catchments. This property is exploited in our experiments with the use of a prior, described in Sect. 4.4.

We limit $d$ to the range $0 \leq d \leq 2$. Values less than zero imply a negative correlation between simulations and observations, and in these cases it is more sensible to ignore the simulation (i.e. to allow $d=0$ ). The upper limit of 2 is arbitrary, and is imposed to avoid unrealistically large corrections being applied under cross-validation.

\subsubsection{Stage 3: autoregressive model}

FoGSS applies a first-order autoregressive (AR1) model (Li et al., 2015) to improve the accuracy of forecasts and to propagate hydrological uncertainty through the forecast lead times. The AR1 model is applied to transformed, biascorrected flows by

$z_{3}(t)=z_{2}(t)+\rho(i)\left(z_{\mathrm{o}}(t-1)-z_{2}(t-1)\right)$, 
where $z_{\mathrm{o}}$ is the transformed observed streamflow and $\rho(i)$ is the autoregression parameter, varied by calendar month. To avoid corrections that are too large, we apply the restriction proposed by Li et al. (2015). This restriction corrects the forecast by whichever is smaller: the correction proposed by Eq. (3), or the error in the original domain at $t-1$ given by $q_{\mathrm{o}}(t-1)-q_{2}(t-1)$ (where $q_{\mathrm{o}}$ is observed streamflow and $q_{2}$ is the back-transformed value of $z_{2}$ ).

\subsubsection{Estimating parameters}

Parameters for each stage are estimated sequentially using maximum likelihood estimation (MLE), as detailed by Bennett et al. (2016). The data transformation (Stage 1) allows us to assume that residuals, $\varepsilon$, are normally distributed and homoscedastic (i.e. the variance does not change). At Stage 3, the residuals are given by

$$
\begin{aligned}
z_{\mathrm{O}}(t) & =z_{3}(t)+\varepsilon(i), \\
\varepsilon(i) & \sim N\left(0, \sigma^{2}(i)\right),
\end{aligned}
$$

where $\sigma^{2}(i)$ is the variance of $\varepsilon$ at each calendar month.

To handle zero values in ephemeral catchments, we treat observations of zero as censored values in the likelihood, a technique established previously (Li et al., 2013).

A notable aspect of the estimation of hydrological and error model parameters is that we take no account of lead time in the parameter estimation. Parameters are estimated only from rainfall-runoff simulations (forced by observed rainfall and potential evaporation) and observed streamflow, as with a conventional rainfall-runoff model calibration. This is a key difference with approaches that post-process streamflow forecasts separately at each lead time (e.g. Yuan, 2016), as it means that each FoGSS time series forecast is a continuous hydrograph that can be summed to produce reliable ensembles of e.g. seasonal inflow totals. However, the FoGSS error model will not correct problems associated with ensemble rainfall forecasts (e.g. overconfident ensembles). FoGSS requires ensemble rainfall forecasts that are unbiased and reliable in order to produce unbiased and reliable streamflow forecasts.

\subsubsection{Generating a forecast: stochastic updating}

Hydrological uncertainty is propagated with stochastic updating. At the first lead time, $l=0$, this is straightforward: we have an observation available when the forecast is issued, and hence we can apply Eq. (3) directly, and then add noise according to Eq. (4) to produce a forecast value $z_{\mathrm{F}}$. At longer lead times $l=1, \ldots, 11$, we substitute the forecast value, $z_{\mathrm{F}}$, for the observation, $z_{\mathrm{o}}$, in Eq. (3), and forecasts are generated by

$$
\begin{aligned}
z_{\mathrm{F}}(t+l) & =z_{2}(t+l)+\rho(i)\left(z_{\mathrm{F}}(t+l-1)-z_{2}(t+l-1)\right) \\
& +\varepsilon(i) \mid l=1, \ldots, 11, \\
\varepsilon(i) & \sim N\left(0, \sigma^{2}(i)\right) .
\end{aligned}
$$

In this way hydrological uncertainty grows through the forecast, as expected (i.e. forecasts become less certain at longer lead times). As with Eq. (3), the restriction (see Sect. 2.3.3) is applied to Eq. (5).

\section{General set-up and data}

\subsection{Forecast cross-validation}

Thorough validation of forecast systems requires a large population of reforecasts to allow testing over a variety of conditions and to be able to calculate robust probabilistic verification scores. Reforecasts are often limited in number, in our case because POAMA reforecasts are only available for 1982-2010 (see Sect. 2.1). Rigorous cross-validation is a vital element of robust forecast validation. We use the following scheme.

1. The post-processing of rainfall forecasts is crossvalidated using leave-3-years-out cross-validation.

2. Hydrological and error models are cross-validated using leave-5-years-out cross-validation.

A more stringent cross-validation is required for hydrological models because catchment memory is more persistent than memory in seasonal weather patterns or SST (i.e. current catchment conditions can influence streamflow for 2 or more years in some catchments).

To estimate parameters and to generate forecasts, the hydrological model is initialized by running it from January 1970 .

\subsection{Verification scores}

In accordance with most studies of ensemble forecasting systems, we are chiefly concerned with two aspects of forecast performance: forecast skill and forecast reliability. To measure forecast skill, we use the well-known continuous ranked probability score (CRPS; see e.g. Gneiting and Katzfuss, 2014). Skill is measured against streamflow climatology. Forecast skill is given by the continuous ranked probability skill score (CRPSS):

$$
\mathrm{CRPSS}=\frac{\mathrm{CRPS}_{\text {Ref }}-\mathrm{CRPS}_{\mathrm{F}}}{\mathrm{CRPS}_{\mathrm{Ref}}} \times 100 \%,
$$

where CRPS $_{\mathrm{F}}$ and $\mathrm{CRPS}_{\mathrm{Ref}}$ are CRPS values for FoGSS and climatology forecasts, respectively. To generate the climatology forecasts, a log-sinh transformed (Eq. 1) normal distribution is fitted to the observed streamflow data for each month. 
When fitting the distribution, zero values are handled with data censoring as described by Wang and Robertson (2011) to ensure the climatology forecasts correctly replicate the observed incidence of zero values. Once the distribution is fitted, 1000 samples are drawn from it to produce the reference forecasts (values below zero are set to zero). Climatology is generated from observations from 1982 to 2009, applying the same leave-5-years-out cross-validation procedure as described for the hydrological modelling (Sect. 3.1). In some very dry catchments, some months recorded only zero flow, and in these cases it is not possible to fit a distribution. Here, we take a pragmatic approach: we simply assign a reference forecast of zero. CRPSS ranges from $-\infty$ (least skilful) to $100 \%$ (perfectly skilful). FoGSS forecasts need not necessarily outperform climatology to function as a viable alternative to stochastic scenarios, but they do need to be at least similarly skilful to climatology. We term forecasts with skills near zero neutrally skilful, defined as $-5 \%>$ CRPSS $<5 \%$.

As noted in the introduction, a key attribute of stochastic scenarios is that they are inherently unbiased and thus can be used directly in planning models by water agencies. To be a viable alternative to stochastic scenarios, FoGSS forecasts should be unbiased. Absolute relative bias (hereafter referred to as "bias") of forecasts is calculated at each lead time, $l$, by

$\operatorname{Bias}(l)=\left|\frac{\overline{q_{\mathrm{F}}(l)}-\overline{q_{\mathrm{o}}}}{\overline{q_{\mathrm{o}}}} \times 100 \%\right|$,

where $\overline{q_{\mathrm{F}}(l)}$ is the mean of all ensemble forecasts at each lead time. Bias ranges from 0 (unbiased) to $+\infty$ (worst bias).

The statistical reliability of ensemble forecasts is assessed with probability integral transform (PIT) uniform probability plots (shortened to PIT plots). Given the cumulative distribution function (CDF) of a forecast at time $t, C_{t}$, the PIT of the accompanying observed value, $q_{\mathrm{o}}(t)$, is given by

$\pi_{t}=C_{t}\left(q_{\mathrm{o}}(t)\right)$.

$\pi_{t}$ takes values from 0 to 1 . When a set of forecasts is reliable, the set of $\pi_{t}$ values is uniformly distributed between 0 and 1 , and the resulting PIT plot will follow the diagonal 1-1 line. In catchments with zero values, the CDF in Eq. (8) will not be continuous (and therefore cannot be expected to follow a uniform distribution). In these catchments, if $q_{\mathrm{o}}(t)=0$, we generate a pseudo-PIT value, $\pi_{t}$, randomly sampled from a uniform distribution in the range $\left[0, C_{t}(0)\right]$.

To compare reliability for many catchments we summarize information from PIT plots with the alpha index (Renard et al., 2010)

$\alpha=1-\frac{2}{n} \sum_{t=1}^{n}\left|\pi_{t}^{*}-\frac{t}{n+1}\right|$,

where $\pi_{t}^{*}$ is the sorted $\pi_{t}$ in increasing order, and $n$ the number of forecasts. The alpha index essentially reflects the divergence of PIT values from the 1-1 line in PIT plots, ranging from 1 (perfectly reliable) to 0 (worst reliability).

\subsection{Catchments and data}

We assess FoGSS forecasts on 63 Australian catchments ranging in size from $<100 \mathrm{~km}^{2}$ to $>200000 \mathrm{~km}^{2}$ (Appendix A). Catchments are distributed across the continent, encompassing temperate, desert, subtropical and tropical climates. Rainfall and potential evaporation data are taken from the gridded AWAP dataset (http://www.bom.gov.au/jsp/ awap), which interpolates gauged observations with a Barnes successive correction analysis (Jones et al., 2009; Raupach et al., 2008). Streamflow data are mainly from gauges, but we have also included several "inflow sites", which are not directly gauged. The inflow site records give total inflow to storages, and are calculated from a combination of streamflow gauge records, storage levels, and discharge from storages. We include these sites because they are of good quality, and often of central importance to water agencies. All streamflow data records have been supplied and checked for quality by the Bureau of Meteorology.

Of the rivers we assess, one-third - 21 catchments - are ephemeral (defined as having zero flows in $>4 \%$ of their records), occurring in both temperate and tropical climates. As ephemeral rivers tend to be very difficult to predict - they can exhibit strongly non-linear responses of runoff to rainfall and they often experience highly sporadic rainfall - we pay particular attention to these catchments. To illustrate different aspects of the performance of FoGSS, we choose a subset of six catchments (Table 1). The streamflow characteristics of these rivers are shown in Fig. 2. Brief descriptions of each catchment are as follows.

- Fitzroy River (Western Australia): ephemeral river with a large catchment area that ceases to flow only occasionally (Fig. 2). Like all northern, tropical regions in Australia, the Fitzroy receives most rainfall in the monsoon period (November-March), and very little rainfall at other times of the year.

- Ranken River (Northern Territory): an extremely dry catchment that ceases to flow for long periods, flowing regularly only in March. The Ranken River can record zero flows at any time of year, and is usually dry from April to December. Over the period 1982-2009, the river never flowed in September.

- Herbert River (Queensland): perennial river that receives the bulk of its rainfall in the monsoon period (November-March).

- Lake Eppalock inflows (Victoria): Lake Eppalock receives inflow from the temperate and seasonally ephemeral Campaspe River, largely during JulyNovember. This is a high-quality inflow series synthesized from stream gauge and storage level records, and often receives zero inflow in late summer to early autumn (January-April). 
Table 1. Case study catchments.

\begin{tabular}{llllrrrr}
\hline Gauge name & Gauge number & State ${ }^{\mathrm{a}}$ & $\begin{array}{l}\text { Perennial/ } \\
\text { ephemeral }\end{array}$ & $\begin{array}{l}\text { Catchment } \\
\text { area }\left(\mathrm{km}^{2}\right)\end{array}$ & $\begin{array}{r}\text { Longitude } \\
\text { Latitude }\end{array}$ & $\begin{array}{c}\text { Missing } \\
\text { data }(\%)\end{array}$ \\
\hline Goobarragandra River above Lacmalac & 410057 & NSW & Perennial & 668 & 148.35 & -35.33 \\
Ranken River at Soudan Homestead & G0010005 & NT & Ephemeral & 4360 & 137.02 & -20.05 & 8.3 \\
Herbert River above Abergowrie & $116006 B$ & QLD & Perennial & 7486 & 145.92 & -18.49 & 0.0 \\
Ringarooma River at Moorina Bridge & 30 & TAS & Perennial & 517 & 147.87 & -41.13 & 8.0 \\
Lake Eppalock inflows (Campaspe River) & Inflows site & VIC & Ephemeral & 1749 & 144.56 & -36.88 & 0.0 \\
Fitzroy River at Fitzroy Crossing Bridge & 802055 & WA & Ephemeral & 46133 & 125.58 & -18.21 & 0.3 \\
\hline
\end{tabular}

a Abbreviations of Australian state names: NSW: New South Wales; NT: Northern Territory; QLD: Queensland; TAS: Tasmania; VIC: Victoria; WA: Western Australia.
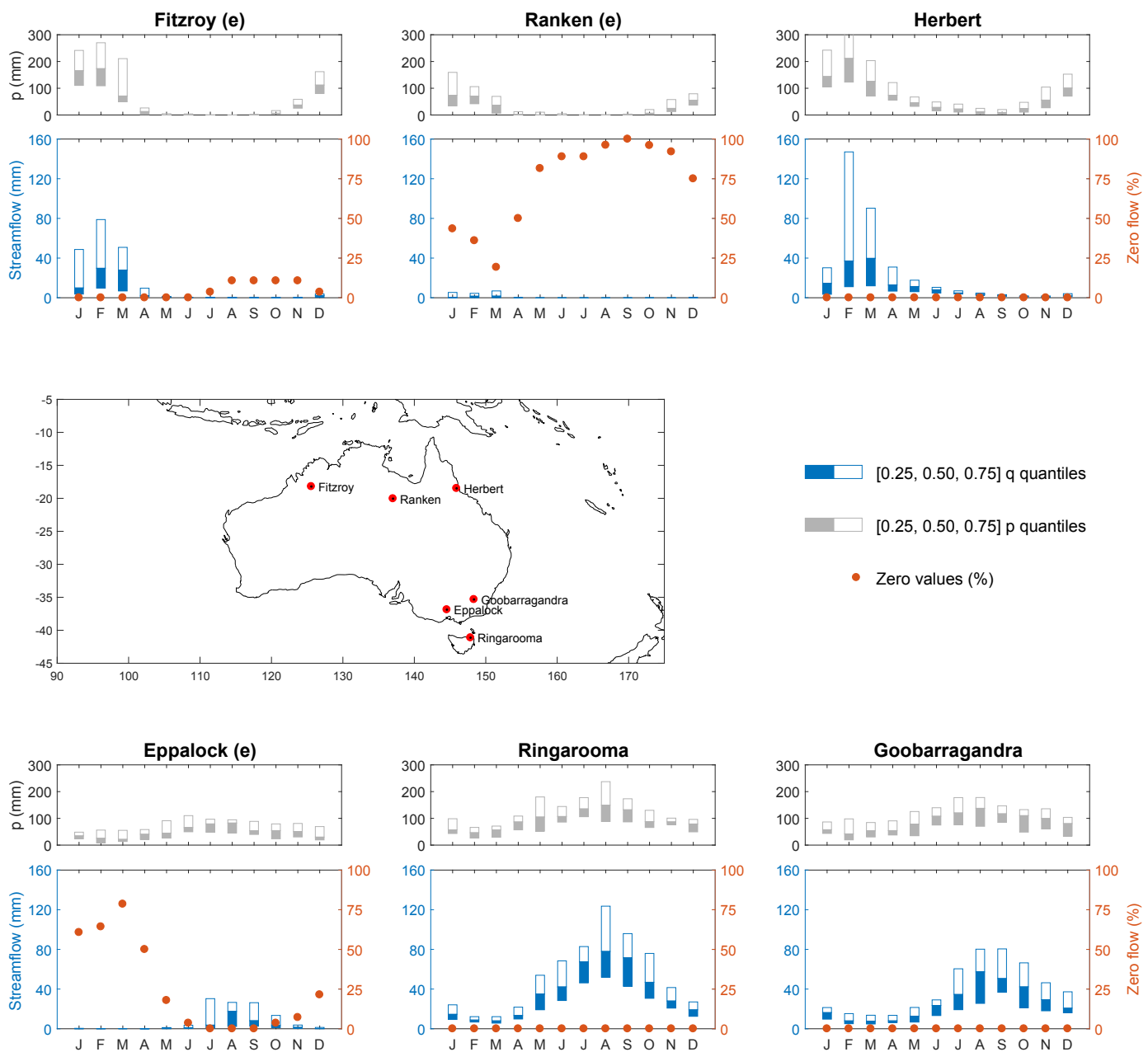

Figure 2. Catchment characteristics of six case study catchments. Ephemeral catchments are denoted by (e). The left axis shows monthly streamflow $(q)$ and rainfall $(p)$ characteristics, with bars showing the interquartile range and median flows for the period 1982-2009. The right axis shows the proportion of zero flows (orange points) in each month for the period 1982-2009.

- Goobarragandra River (New South Wales): perennial river that receives most rainfall in winter and spring (June-November). This catchment generally exhibits strong catchment memory.
- Ringarooma River (Tasmania): alpine, temperate river that receives regular, winter dominant rainfall (JuneAugust), but has little catchment memory. 


\section{Experiments}

\subsection{Base case: continent-wide performance assessment of FoGSS}

To establish whether FoGSS is a system capable of being deployed across the Australian continent, we test FoGSS as it was described by Bennett et al. (2016): that is, as described in Sect. 2, using the Wapaba rainfall-runoff model. This constitutes the base case, against which the following variations will be tested. The performance of the base case is assessed by skill, reliability and bias (Sect. 3.2).

\subsection{Experiment 1: contribution of rainfall forecasts to skill}

To assess the contribution of rainfall forecasts to overall streamflow forecast skill, we compare our base case to ESPlike forecasts (extended streamflow predictions). Traditional ESP methods use resampled historical rainfall to force an initialized hydrological model (Day, 1985). An ensemble of historical rainfall forcings is reliable and unbiased but completely uninformative, so any forecast skill remaining will be due to catchment memory (Wood and Lettenmaier, 2008). We use a similar approach, except that we also apply the FoGSS hydrological error model. By comparing streamflow forecasts generated with ESP-like historical rainfall forcings to those generated with the full FoGSS system, we can determine the relative contribution of post-processed POAMA forecasts to overall forecast skill. Historical rainfall forcings are sampled from observations from 1982 to 2009, using a leave-4-years-out cross-validation scheme. (The leave-4years-out scheme was chosen in part for computational convenience: it results in a forcing ensemble of 25 members, which divides evenly into 1000, the size of the FoGSS ensemble.) To produce a 1000-member ensemble, we run each historical rainfall sequence through the FoGSS hydrological and error models 40 times, using a different random seed at the start of each run. To keep the distinction clear, we refer to the post-processed POAMA forcings as forecast rainfall to distinguish them from the ESP-like historical rainfall forcings.

\subsection{Experiment 2: hydrological modelling}

As already noted, the original conception of FoGSS made use of the Wapaba rainfall-runoff model (Wang et al., 2011). Wapaba is a five-parameter conceptual hydrological model based on the Budyko curve, which casts the water balance as a competition between available water and available energy. Its parameters and a schematic of its structure are given in Appendix B. Wapaba performed well in a study that compared it to other rainfall-runoff models for simulating 331 (largely) perennial Australian rivers (Wang et al., 2011). However, as we will see, Wapaba's performance is more equivocal for forecasts of ephemeral rivers.
To test whether performance can be improved using alternative rainfall-runoff models, we substitute two alternative monthly rainfall-runoff models, ABCD and GR2M, into the FoGSS system. ABCD (Thomas, 1981; Alley, 1984) is a four-parameter monthly water balance model and GR2M (Mouelhi et al., 2006) is a simpler model with two parameters. Parameters and structures of the two models are shown in Appendix B. In general, ABCD and Wapaba are more similar to each other than to GR2M. ABCD and Wapaba each have two parameters to control the apportionment of water between the surface water store and groundwater/direct runoff, while GR2M simply relies on an empirical equation for this apportionment. All three models have two conceptual soil moisture stores, but they function slightly differently in each case. The surface stores in ABCD and Wapaba can lose water only to evaporation or when the storage spills. GR2M's production store loses water to evaporation and spill, but also drains to the routing store at a non-linear rate in relation to the level of the production store. ABCD and Wapaba both have groundwater stores of unlimited capacity and both have parameters to control the (linear) rate of discharge from the groundwater store. GR2M has a finite (and fixed) groundwater storage capacity, and uses a fixed (non-linear) relationship to govern discharge from its routing store. In both Wapaba and $\mathrm{ABCD}$, catchment losses are entirely controlled by evaporation. In GR2M water can be lost to, or gained from, an unlimited conceptual groundwater store outside the catchment. Wapaba and ABCD differ in the way that they apportion water between soil moisture stores and groundwater and direct runoff, and have different methods to calculate actual evaporation from the surface store.

Rainfall-runoff model parameters are estimated using maximum likelihood. Parameters of the subsequent stages of the error model (stages 2 and 3) are then estimated, as described in Sect. 2.3.4. That is, only the rainfall-runoff models and Stage 2 and Stage 3 error model parameters change in this experiment: all other elements of FoGSS remain the same.

\subsection{Experiment 3: encouraging the error model to return climatology forecasts}

As we shall see, the FoGSS system is outperformed by climatology in some very dry catchments. One way to achieve "coherent" forecasts (i.e. where forecasts are at least neutrally skilful) is to encourage the error model to return climatology forecasts in instances where there are few non-zero streamflows. We do this by pushing the $d$ parameter in the bias-correction (Eq. 2) towards zero. That is, we encourage the error model to discount information from the forecast and to return a climatology $\left(z_{2} \approx \mu\right)$. This is achieved by placing an informative Bayesian prior on the $d$ parameter:

$d \sim N\left(0, \sigma_{d}^{2}\right)$, 

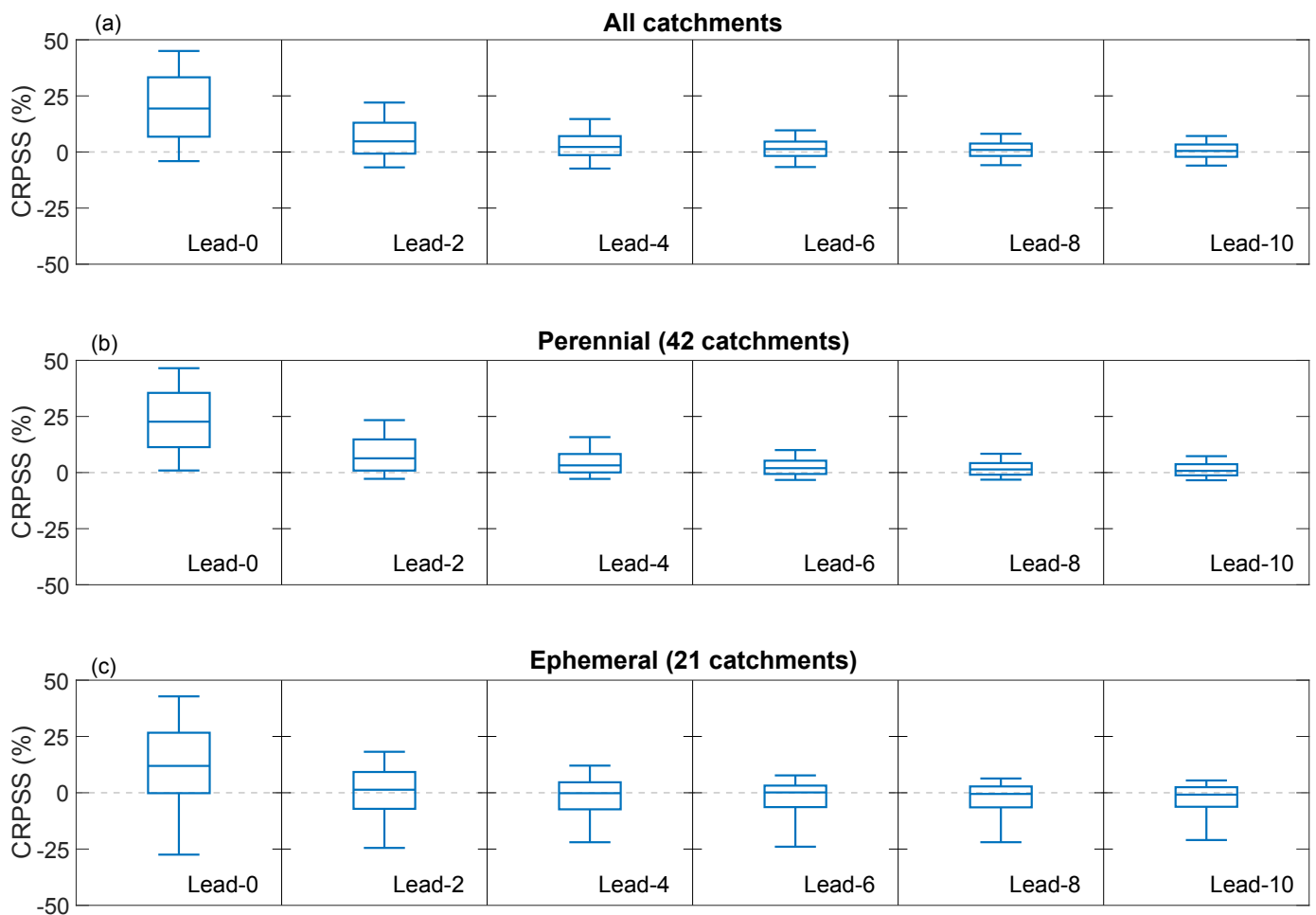

Figure 3. Forecast skill (CRPSS) for 63 catchments by lead time for the FoGSS base case. For each lead time, forecast skill is summarized for all months and catchments with box and whisker plots. Boxes show the interquartile range with the median; whiskers give the 10th and 90th percentiles. (a) shows all catchments, (b) shows perennial catchments, and (c) shows ephemeral catchments.

where the standard deviation, $\sigma_{d}$, controls the strength of the prior: smaller values encourage $d$ to take values closer to zero. We test the values $\sigma_{d}=0.25,0.5,1.0,2.0$, and 4.0 . Because of the use of the prior, this estimation approach is no longer formally MLE, but a maximum a posteriori (MAP) estimation. The posterior density used to estimate the parameters is given in Appendix C (Eq. C3).

\section{Results and discussion}

\subsection{Continent-wide performance of the base FoGSS model}

Forecast skill for all catchments is summarized in Fig. 3. At very short lead times (e.g. lead-0), FoGSS forecasts are very often skilful. Skill at lead-0 is overwhelmingly positive in perennial catchments, and is generally also positive in ephemeral catchments. Skill subsides with lead time, with forecast skill in ephemeral catchments declining more rapidly. By lead-6, forecasts are generally neutrally skilful for all catchments. Instances of strongly negative skill $(<-15 \%)$ are rare in perennial catchments, and also absent in a substantial number of ephemeral catchments. Strongly negative skills do occur in a few very dry ephemeral catchments, as described for the Ranken catchment below. Anal- ysis of reliability and bias for all 63 catchments will be described in the results of the three experiments (Sect. 5.2-5.4).

To illustrate the overall performance of the FoGSS base case, we review skill and reliability for the six case study catchments. The strong performance of FoGSS in perennial catchments is reflected in the Herbert, Goobarragandra and Ringarooma rivers, shown in Fig. 4. Forecasts are generally skilful at shorter lead times (typically $<3$ months), and thereafter become neutrally skilful. There is, however, considerable variation in performance: forecasts can be strongly skilful to long lead times (e.g. 6 months or more in the Goobarragandra River), while catchments with little catchment memory (e.g. the Ringarooma River) may only be skilful to lead0 (i.e. in the first month). Some moderately negative skills do occur in the Herbert catchment, in low-flow months at longer lead times (e.g. August). These are caused by slight mispredictions of flow issued in wetter months (e.g. February), which result in proportionally larger errors in drier months at longer lead times. FoGSS also performs well in the ephemeral Fitzroy catchment, returning largely positive or neutral skill, with only a few isolated instances of slightly negative skill.

In more strongly ephemeral catchments, performance can be poor. In the seasonally ephemeral Eppalock catchment, forecast skill is strongly negative in the dry months from January to April, although the forecasts perform well at other 

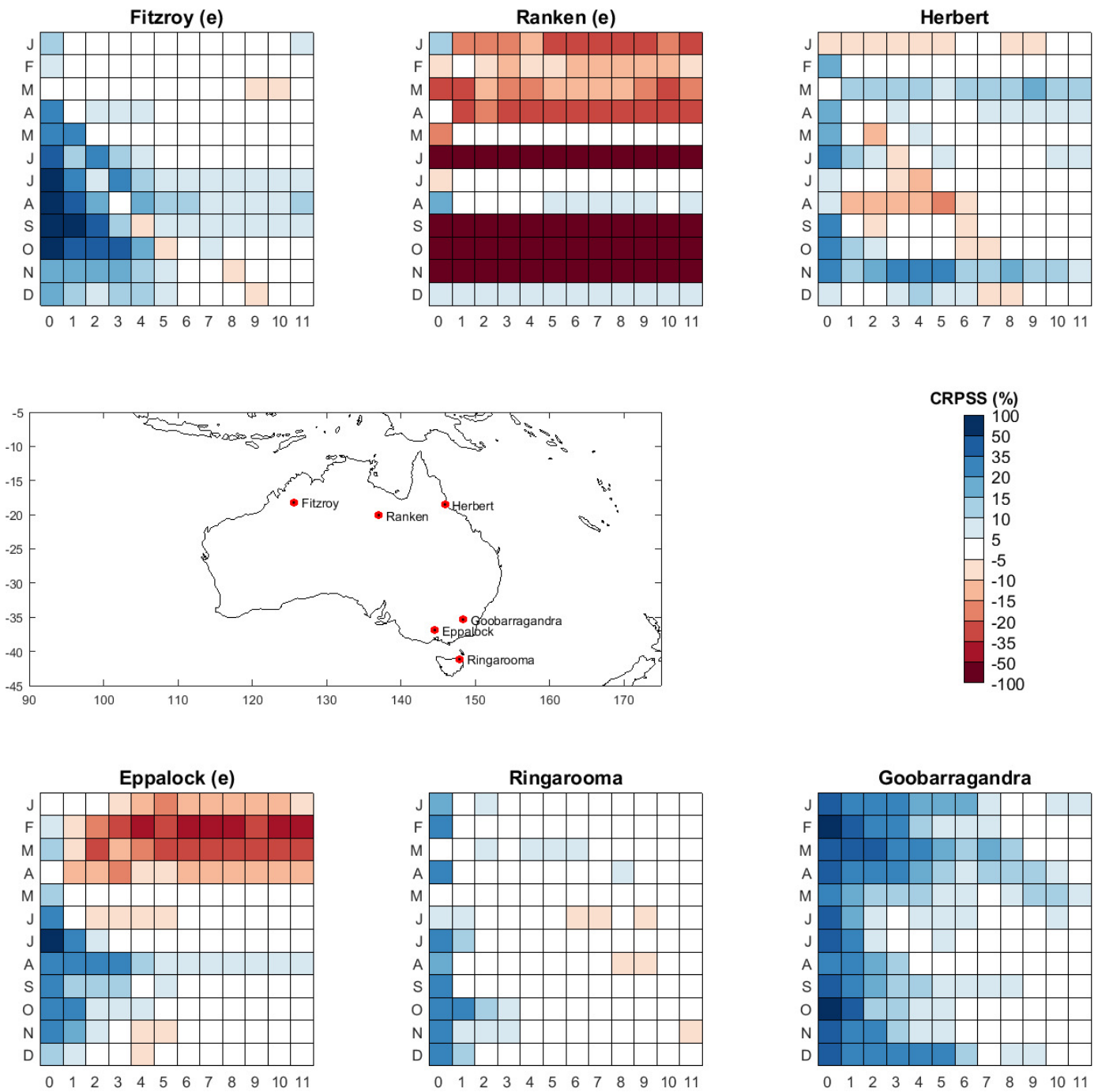

Figure 4. Skill (CRPSS) for FoGSS forecasts (base case). Ephemeral catchments are denoted with (e). Target months are shown on the vertical axes, and target lead times on the horizontal axes. Centre map gives catchment locations.

times of the year. In the Ranken catchment, which experiences high incidences of zero flows year-round, performance is poor for the majority of months and lead times.

The cause of the poor forecast skill in the Ranken and Eppalock catchments is evident when we consider PIT plots (Fig. 5). Forecasts are highly reliable for the perennial Herbert, Ringarooma and Goobarragandra catchments, as well as the Fitzroy catchment, for all months and lead times. Forecasts are not reliable for the dry months of the Eppalock catchment (see February in Fig. 4), and are particularly unreliable for drier months in the Ranken catchment (e.g. September). The bowed shape of the PIT plots in Eppalock is evidence of a persistent bias - a tendency to overestimate flows - in the drier months, driven by an underestimation of the incidence of zero flows. The same problem exists in the Ranken catchment, but to a stronger degree. We have established in earlier work that post-processing rainfall forecasts with $\mathrm{CBaM}$ is able to produce highly reliable forecast rainfall ensembles (e.g. Peng et al., 2014; Schepen et al., 2012), meaning the problem lies with the hydrological error model. In catchments where more than half of streamflow observations are zero, FoGSS will always underestimate the incidence of zero flows. This is because the error model is assumed to follow a symmetrical distribution (Gaussian after transformation) about the value of the forecast. Even if the forecast is zero before the error model is applied, randomly drawing from a symmetrical distribution will yield $\sim 50 \%$ of values greater than zero. We will see in the following experiments that this can have a particularly strong influence on bias. 

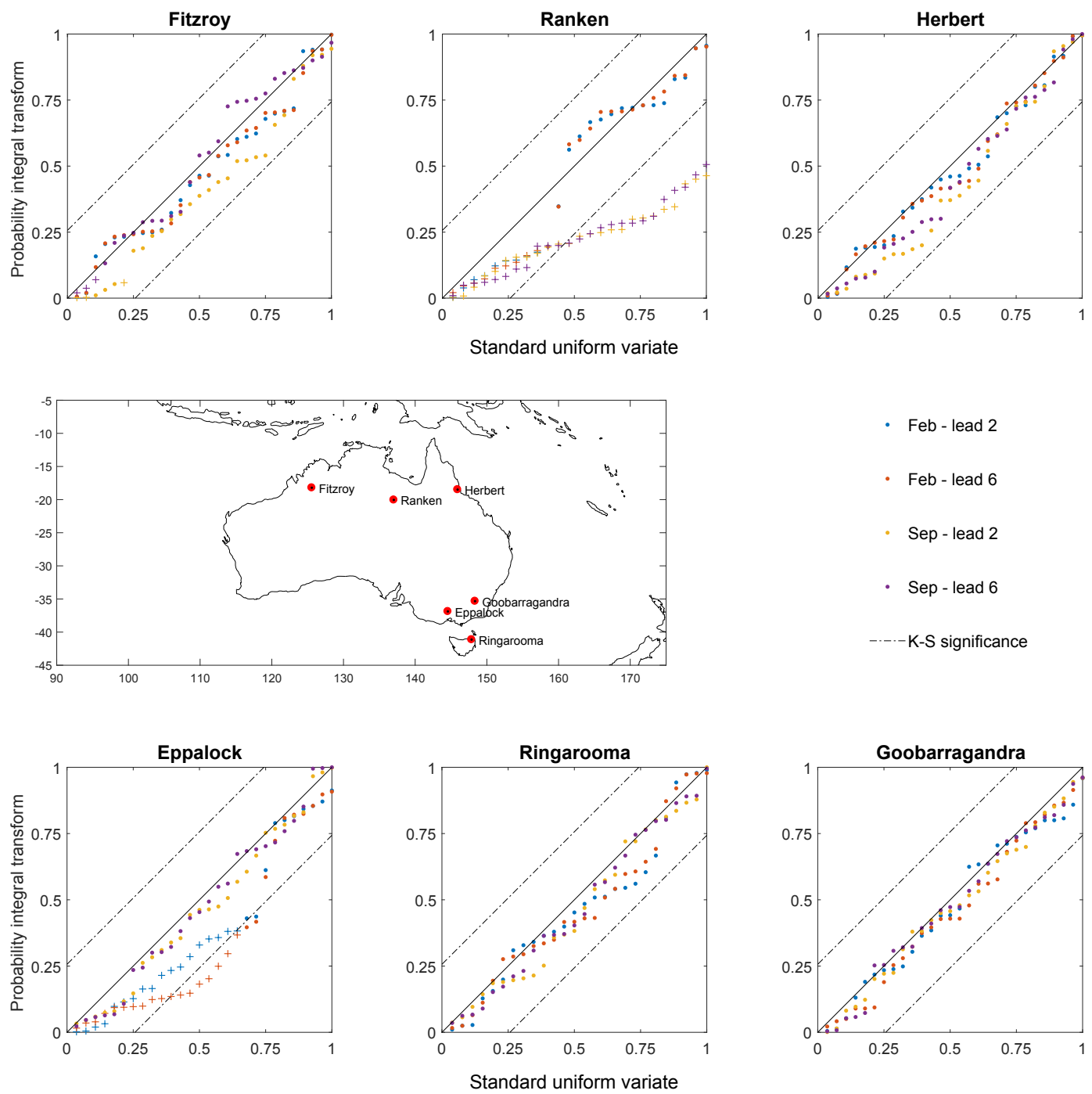

Figure 5. PIT plots for selected months and lead times for FoGSS forecasts (base case). Points are PIT values; crosses are pseudo-PIT values. Centre map gives catchment locations. Dashed lines give Kolmogorov-Smirnoff significance tests at $5 \%$.

\subsection{Experiment 1: contribution of rainfall forecasts to skill}

Figure 6 summarizes how forecast skill varies with lead time for all 63 catchments with both forecast and historical rainfall forcings. Skill at individual lead times is generally not strongly influenced by changing the rainfall forcing to ESP. This highlights the predominant role catchment memory plays in generating skilful forecasts. Forecast rainfall tends to produce slightly more skilful forecasts at lead3 and lead- 6 in perennial catchments but more instances of negative skill at longer lead times (e.g. lead-9). Conversely, in ephemeral catchments historical rainfall forcings tend to produce slightly more skilful streamflow forecasts than forecast rainfall forcings at all lead times.

Forecast rainfall shows slightly more evident benefits, however, when we consider forecasts of accumulated vol- umes. Figure 7 shows forecast skill calculated for forecasts of total streamflow volume accumulated over 1-, 3-, 6-, 9and 12-month periods. In ephemeral catchments, ESP forecasts are slightly better, with fewer instances of strongly negative skill, particularly for shorter accumulation volumes. In perennial catchments, however, forecast rainfall produces slightly, but noticeably, more skilful streamflow forecasts for accumulation periods of 6 months or more. We note that FoGSS forecasts for perennial catchments generally exhibit positive skill for accumulation periods up to 6 months, whichever rainfall forcing is used. This is clear evidence that FoGSS forecasts hold more useful information than stochastic scenarios.

Historical rainfall forcings do, however, have a clear advantage in reducing bias, particularly in ephemeral catchments (Fig. 8). Bias is calculated using the mean of the forecast ensemble. Because the BJP models used to post- 

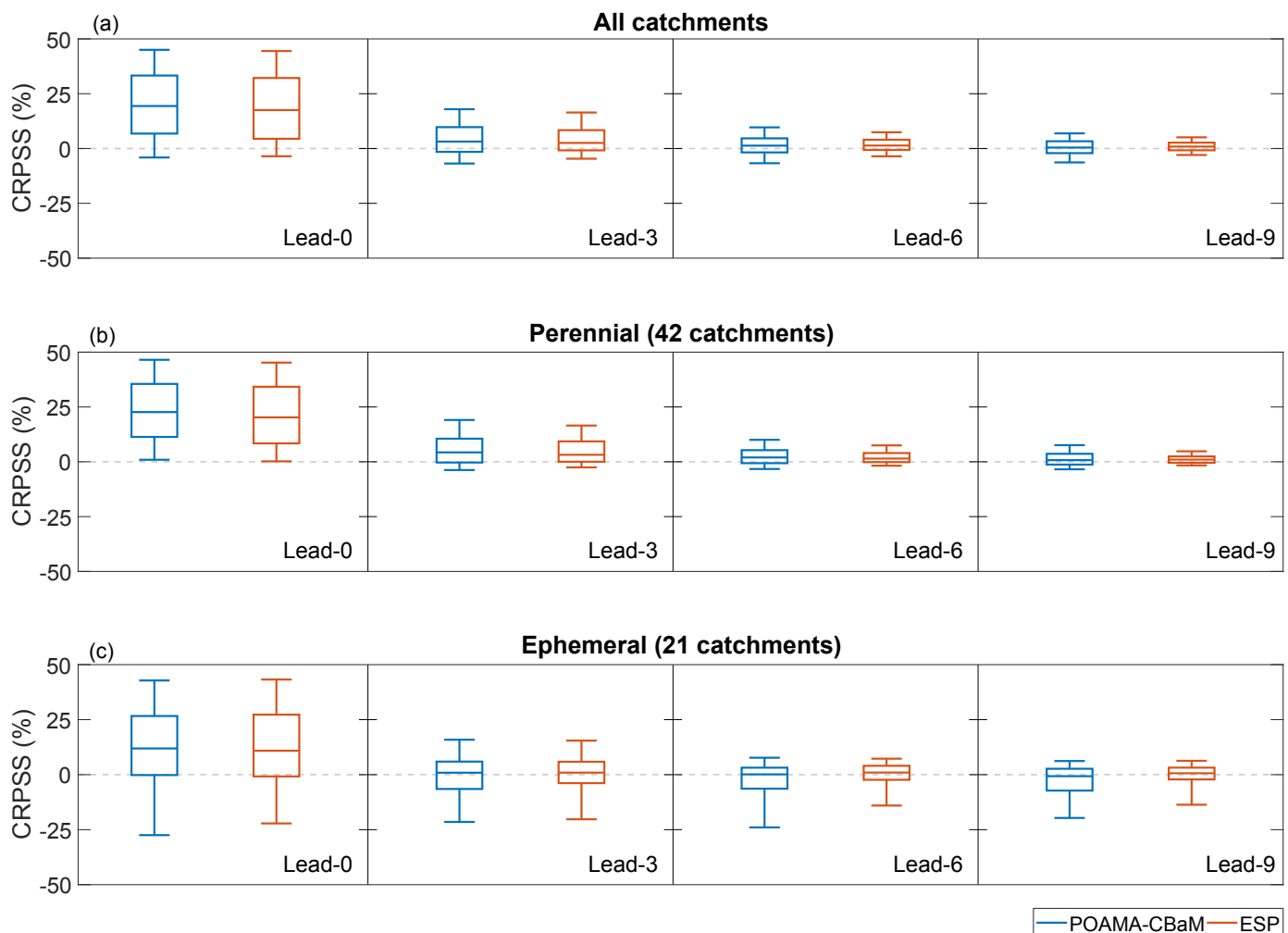

Figure 6. Skill (CRPSS) for 63 catchments by lead time for FoGSS forecasts forced by forecast (POAMA-CBaM) and historical (ESP) rainfall. For each lead time, forecast skill is summarized for all months and catchments with box and whisker plots. Boxes show the interquartile range with the median; whiskers give the 10th and 90th percentiles. (a) shows all catchments, (b) shows perennial catchments, and (c) shows ephemeral catchments.

process POAMA make use of data transformation, the forecasts are unbiased in the transform domain. However, the back-transformation causes the mean of the forecast ensemble to become separated from (and larger than) the ensemble median, resulting in positive biases. These positive biases are often slight $(\sim 5 \%)$, but can be amplified by the rainfallrunoff model. This amplification is particularly prevalent in ephemeral catchments, where the responses of runoff to rainfall can be highly non-linear. We note, however, that even with historical rainfall forcings, streamflow forecasts can be heavily biased. In very dry catchments this is partly due to the underestimation of the incidence of zero flows by the error model, as described in Sect. 5.1 above.

Streamflow forecasts generated from historical rainfall forcings show similar reliability to those generated with forecast rainfall forcings (not shown for brevity).

\subsection{Experiment 2: hydrological modelling}

Figures 9 and 10 show how forecast skill and bias vary with the choice of rainfall-runoff model. In general, the skill is similar for all three models, but both GR2M and Wapaba are noticeably less biased than ABCD. Wapaba and GR2M are similarly skilful and exhibit similar biases in peren- nial catchments. GR2M moderates some of the very negative skill scores and high catchment biases produced by Wapaba in very dry ephemeral catchments, which suggests that Wapaba's infinite groundwater store is not well suited to ephemeral rivers. Like many models, Wapaba can underestimate flows in wet seasons by pushing too much water into groundwater stores and diverting too little through direct runoff. These underestimations have little impact on forecast skill in high-flow months. However, the excess water that is pushed into the infinite groundwater store cannot be lost, so it eventually drains out in dry seasons. This can result in substantial overestimation of streamflow in very dry seasons, which causes high proportional errors and biases. While we apply a bias-correction in the error model, Wapaba's overestimation in dry months is caused by isolated (i.e. rare) events, which are difficult to capture under cross-validation. GR2M's ability to destroy water held in its groundwater store appears to be important for accounting for the high losses that can occur in drylands. GR2M requires the error model to do less work, making the system less prone to errors/bias under cross-validation in ephemeral rivers.

A noteworthy finding of this experiment is that the choice of rainfall-runoff model did not have a major impact on forecast skill in perennial catchments. While a considerable 

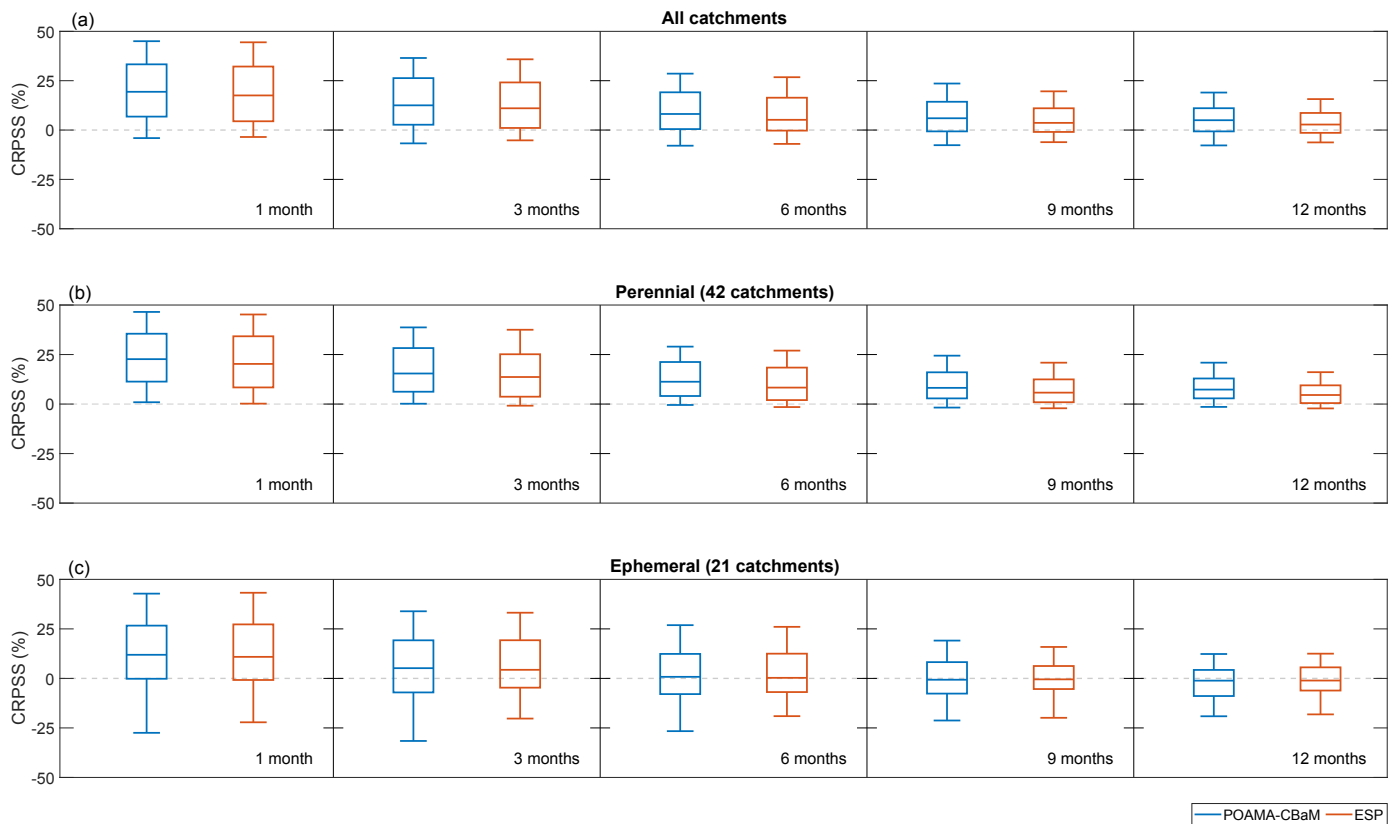

Figure 7. Skill (CRPSS) for 63 catchments by the forecast accumulation period for FoGSS forecasts forced by forecast (POAMA-CBaM) and historical (ESP) rainfall. For each lead time, forecast skill is summarized for all months and catchments with box and whisker plots. Boxes show the interquartile range with the median; whiskers give the 10th and 90th percentiles. (a) shows all catchments, (b) shows perennial catchments, and (c) shows ephemeral catchments.
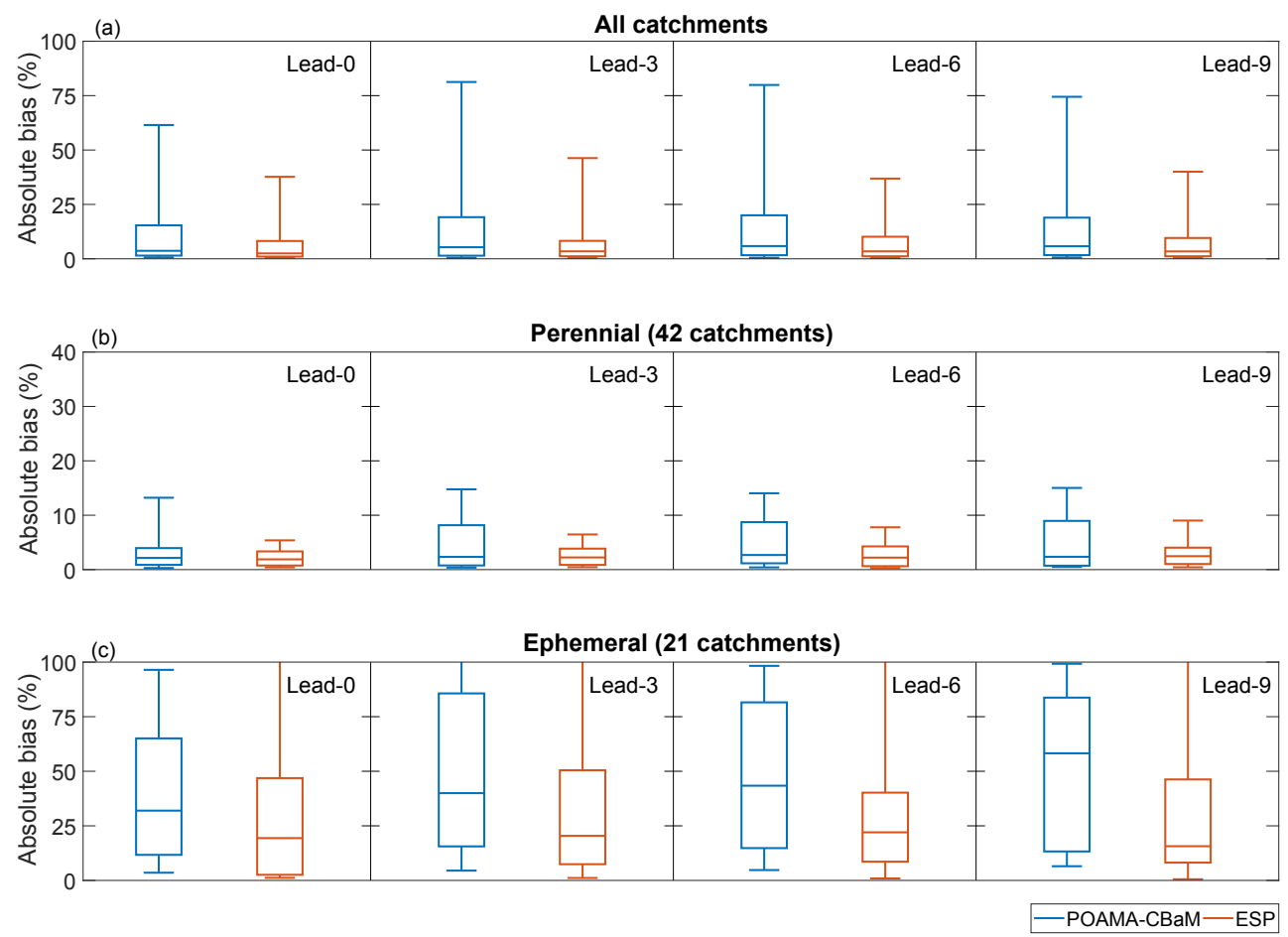

Figure 8. Absolute bias in 63 catchments by lead time for FoGSS forecasts forced by forecast (POAMA-CBaM) and historical (ESP) rainfall. For each lead time, absolute bias is calculated for all months, and then summarized for all catchments with box and whisker plots. Boxes show the interquartile range with the median; whiskers give the 10th and 90th percentiles. (a) shows all catchments, (b) shows perennial catchments, and (c) shows ephemeral catchments. Note the differently scaled vertical axis of (b). 

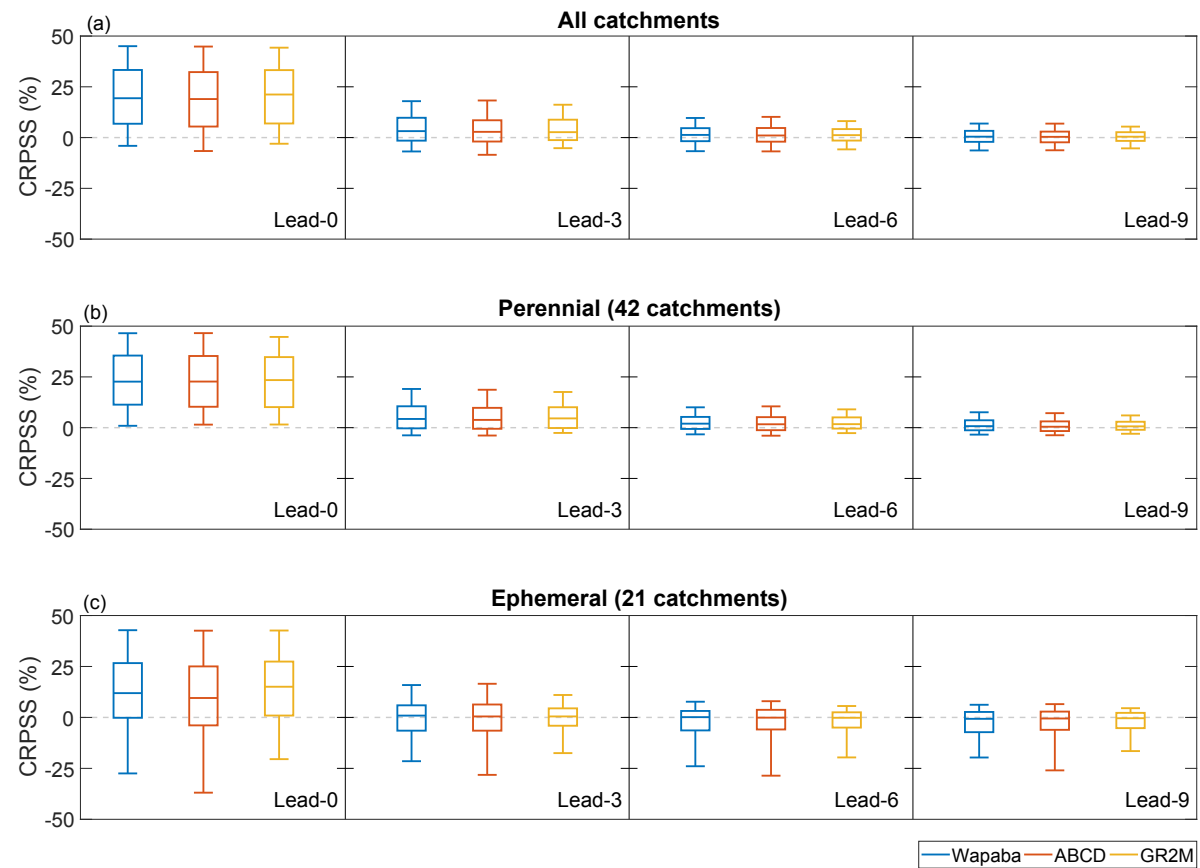

Figure 9. Skill (CRPSS) in 63 catchments by lead time for FoGSS forecasts with different rainfall-runoff models. For each lead time, forecast skill is summarized for all months with box and whisker plots. Boxes show the interquartile range with the median; whiskers give the 10th and 90th percentiles. (a) shows all catchments, (b) shows perennial catchments, and (c) shows ephemeral catchments.
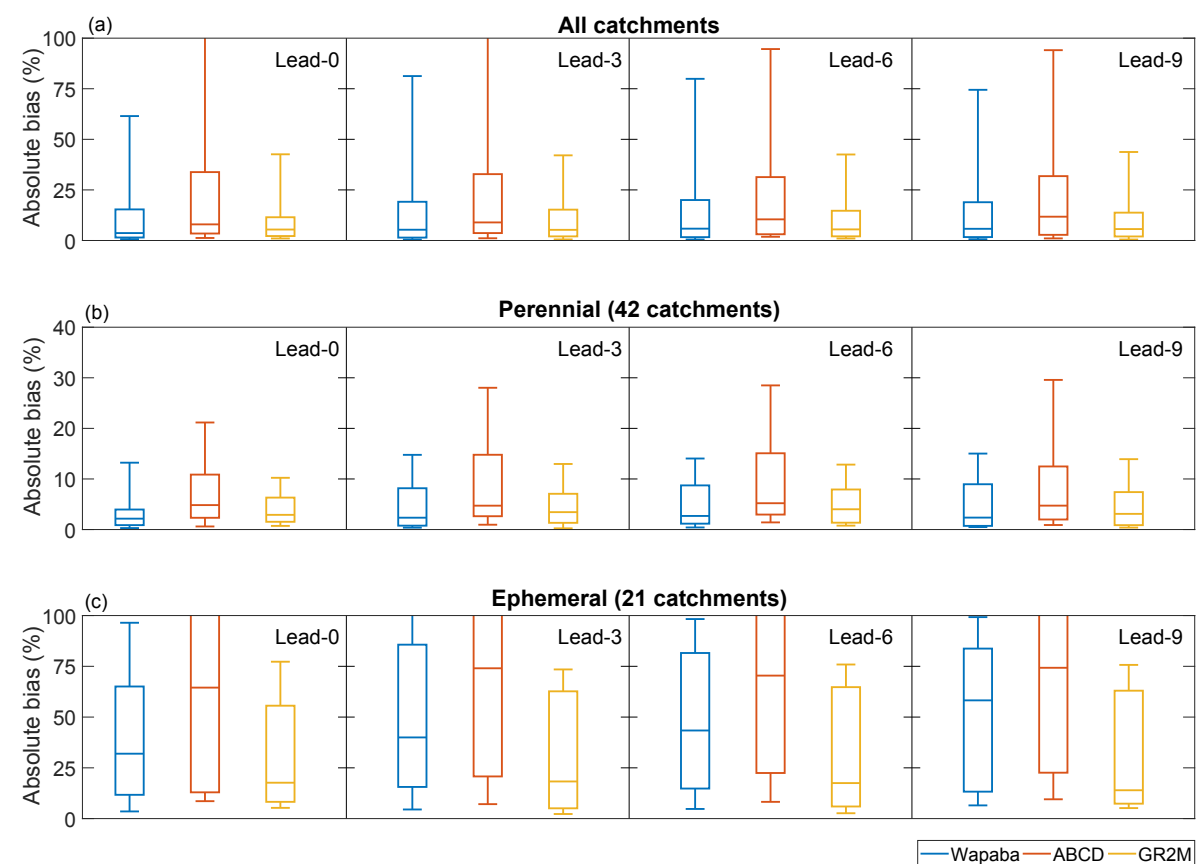

Figure 10. Absolute bias in 63 catchments by lead time for FoGSS forecasts with different rainfall-runoff models. For each lead time absolute bias is summarized for all months with box and whisker plots. Boxes show the interquartile range with the median; whiskers give the 10th and 90th percentiles. (a) shows all catchments, (b) shows perennial catchments, and (c) shows ephemeral catchments. 

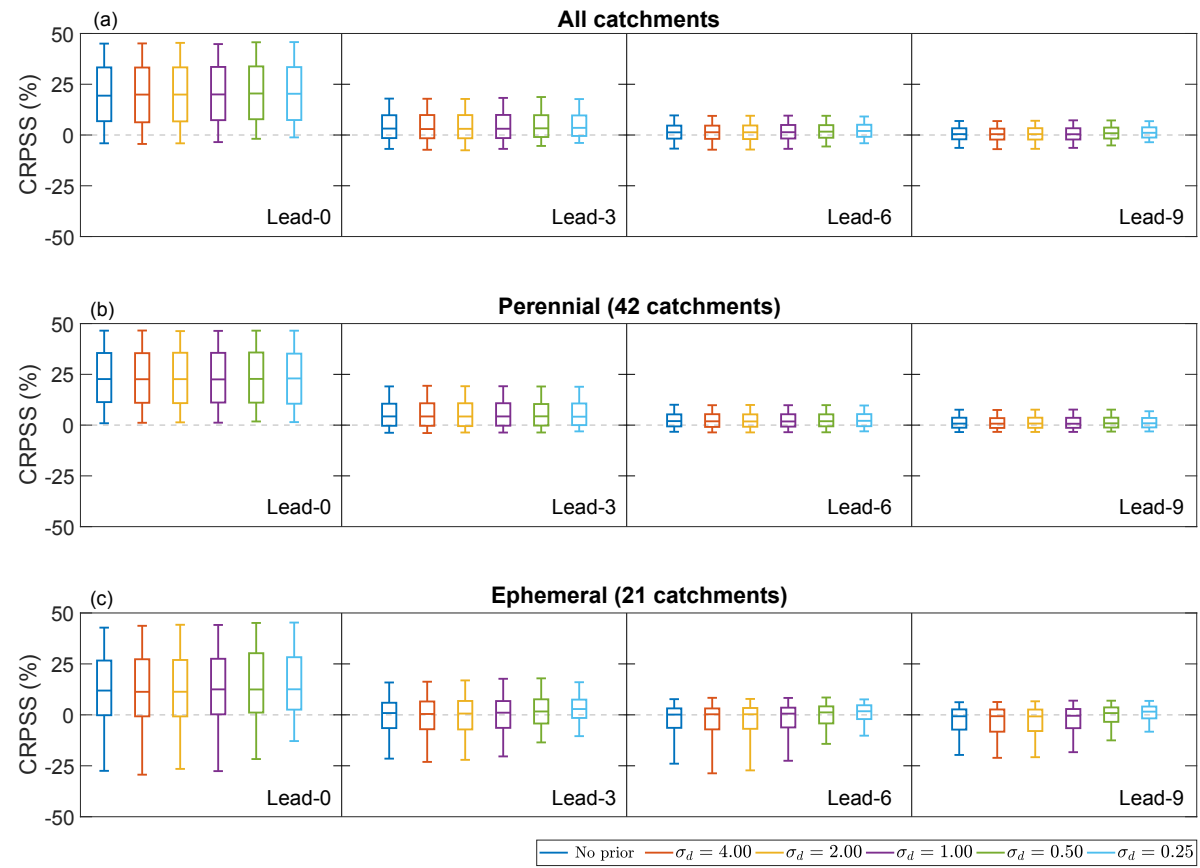

Figure 11. Skill (CRPSS) in 63 catchments by lead time for FoGSS forecasts with different strength priors on the $d$ parameter (smaller values of $\sigma_{d}$ result in a stronger prior). For each lead time, forecast skill is summarized for all months with box and whisker plots. Boxes show the interquartile range with the median; whiskers give the 10th and 90th percentiles. (a) shows results for all catchments, (b) for perennial catchments only, and (c) for ephemeral catchments.
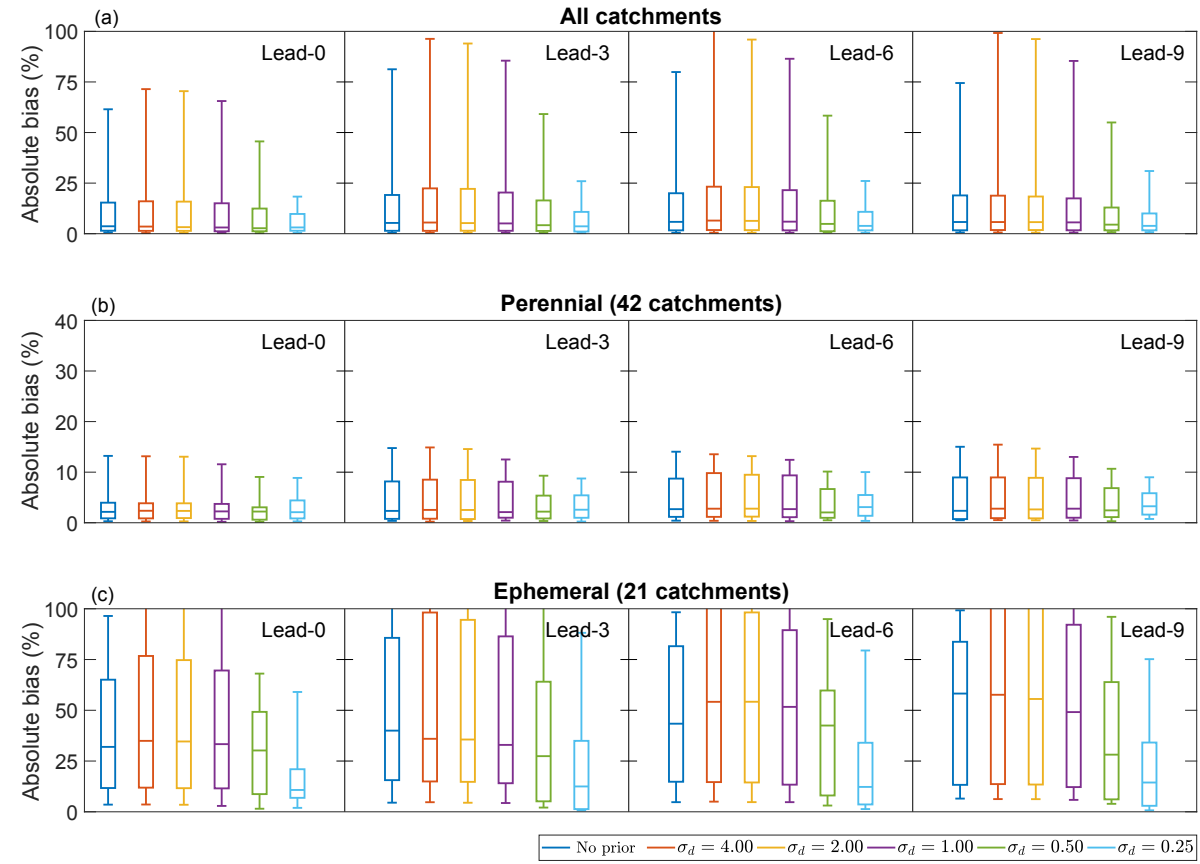

Figure 12. Absolute bias in 63 catchments by lead time for FoGSS forecasts with different strength priors on the $d$ parameter (smaller values of $\sigma_{d}$ result in a stronger prior). For each lead time, absolute bias is summarized for all months with box and whisker plots. Boxes show the interquartile range with the median; whiskers give the 10th and 90th percentiles. (a) shows results for all catchments, (b) for perennial catchments only, and (c) for ephemeral catchments. Note the differently scaled vertical axis of (b). 

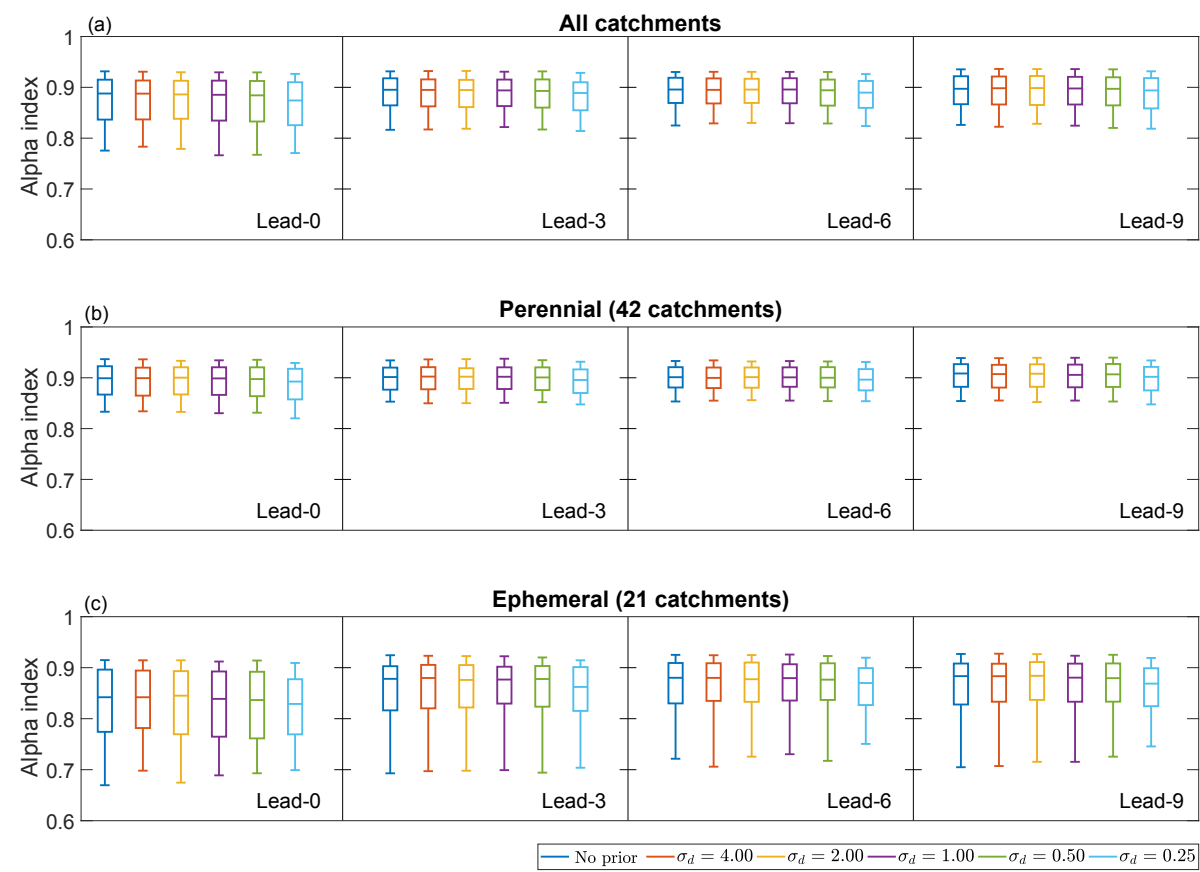

Figure 13. Reliability (alpha index) in 63 catchments by lead time for FoGSS forecasts with different strength priors on the $d$ parameter (smaller values of $\sigma_{d}$ result in a stronger prior). For each lead time, reliability is summarized for all months with box and whisker plots. Boxes show the interquartile range with the median; whiskers give the 10th and 90th percentiles. (a) shows all catchments, (b) shows perennial catchments, and (c) shows ephemeral catchments.

amount of effort is often expended on selecting rainfallrunoff models for particular purposes, our results suggest that, at least at the monthly time step, a well-designed error model can mitigate various deficiencies in rainfall-runoff models for wide-scale application to perennial rivers.

\subsection{Experiment 3: encouraging the error model to return climatology forecasts}

As we expect, the application of a prior on the $d$ parameter has negligible effect on the skill of forecasts in perennial rivers at all lead times (Fig. 11). However, applying the prior did reduce some of the strongly negative skills experienced in ephemeral catchments at all lead times. The stronger the prior (i.e. the smaller the value of $\sigma_{d}$ ), the greater the removal of negative skills, with the effect of the prior becoming negligible for $\sigma_{d} \geq 2.0$. Similarly, bias is greatly reduced by applying a strong prior to ephemeral rivers (Fig. 12), as the forecasts have a reduced tendency to overestimate flows in very dry months. Interestingly, applying a strong prior also reduced biases in perennial catchments. This indicates that the prior is guarding against overfitting of the bias-correction in these instances, with virtually no reduction in positive forecast skill. The reduction in bias has a slight positive impact on reliability in ephemeral rivers at longer lead times, as shown by the alpha index in Fig. 13. However, the prior is unable to address the fundamental inability of FoGSS to generate a sufficient number of zero flows in months where more than half of the observed flows are zero, as discussed in Sect. 5.1.

In summary, the prior encourages FoGSS to behave sensibly. As already noted, strongly negative skills generally only occur in very dry months, where there may be only a few non-zero observations on which to optimize the hydrological and error models. In these cases, it is sensible to encourage FoGSS to return a climatology-like forecast. Conversely, when there are sufficient data to inform the estimation of model parameters and the models perform well, the system should use the models. Using a prior in a MAP optimization enforces this sensible behaviour in the FoGSS system.

\subsection{Synthesis}

In each experiment, variations on the base case resulted in changes in forecast performance, although these changes were sometimes very slight. The use of historical rainfall forcings (Experiment 1) is the least beneficial of the changes. Historical rainfall forcings can reduce bias, and this leads to fewer strongly negative skills, largely in very dry months and catchments. We note, however, that the use of a strong prior has a stronger ability to remove bias in dry months than historical forcings (not shown), thus nullifying the benefits of the historical forcing. The use of historical forcings comes at the cost of removing information available from climate forecasts. We have shown that skill from climate forecasts can accumulate to produce skilful long-range total inflow fore- 

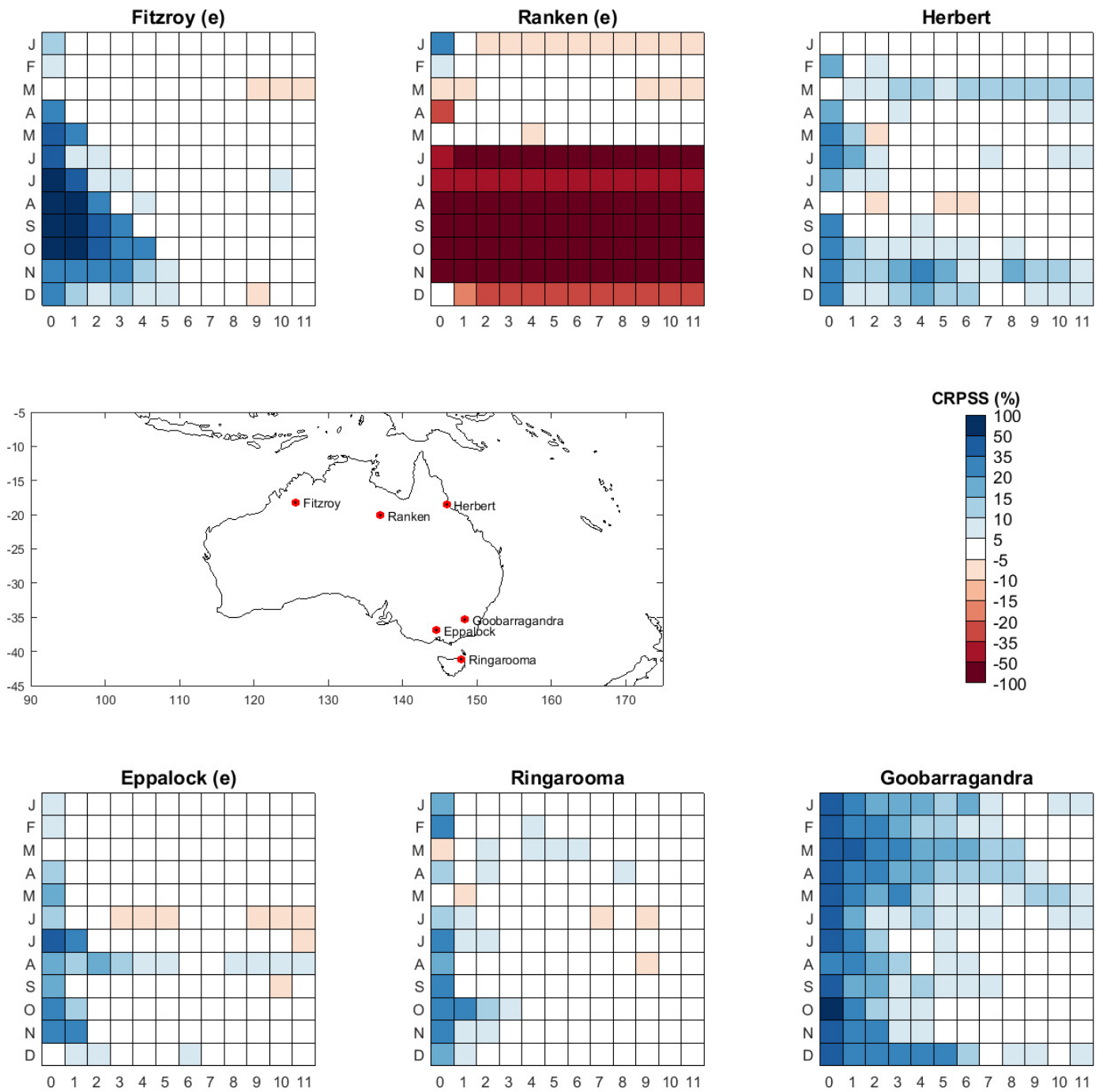

Figure 14. Skill (CRPSS) of FoGSS forecasts generated with the GR2M hydrological model and with a strong prior on the $d$ parameter of $\sigma_{d}=0.25$. Ephemeral catchments are denoted by (e). Target months are shown on the vertical axes, and target lead times on the horizontal axes. Centre map gives catchment locations.

casts. In addition, the POAMA model is being upgraded to a much higher-resolution climate forecasting system by the Bureau of Meteorology (ACCESS-S), and this should result in stronger skill. On balance, the inclusion of climate forecasts is beneficial, not only for the additional skill available in some months/catchments with post-processed POAMA forecasts, but also for the prospect of including better climate forecasts in future.

To show the effects of the other variations (experiments 2 and 3), we combine forecast rainfall forcings with the GR2M model and a strong prior on $d\left(\sigma_{d}=0.25\right)$, and show forecast skill for our six example catchments in Fig. 14. There are some key differences between Fig. 14 and forecast skill of the base case (Fig. 4). In the very dry Ranken catchment, negative skill in wetter months (January-April) is largely removed, in favour of climatology-like forecasts. Conversely, skill in July, August and December has changed from neutral/positive in the base case to be substantially negative. All 3 of these months are very dry in the Ranken catchment (most flows are zero), but feature a single very large event in the record ( $>10 \times$ larger than the next largest measured flow). In these cases, the prior on $d$ has a deleterious effect: allowing $d$ to take a larger range of values better corrects the extremely non-linear biases in these months. When the prior is applied, the bias-correction is not as effective, forcing the error model to take larger values of $\sigma^{2}$. This leads to persistent overestimations of streamflow in the other (very dry) years, leading to negative skill. In the Eppalock catchment, the variations on the base case have an unequivocal benefit: negative skill in the dry months of January-April is completely removed. In the other five catchments, the changes generally either improve or have little impact on base case forecasts. There is 
little change to skill in the Fitzroy catchment (slight reductions in skill in July-September at long lead times), negative skill in the Herbert catchment in August is largely eliminated, and there are no discernible differences in skill in the Ringarooma and Goobarragandra catchments.

As already noted, the GR2M model's main benefit is in ephemeral catchments. In our example catchments in Fig. 14, GR2M acts mainly to reduce negative skills in the Eppalock catchment in February and March by reducing bias, with little differences in other catchments. As with the benefits of historical rainfall forcings, however, the ability of GR2M to reduce bias is largely subsumed by the use of a strong prior on the $d$ parameter: similar reductions in negative skill in Eppalock are achieved when a prior on $d$ is applied with the Wapaba model (not shown).

The use of a strong prior on $d$ results in neutral to positive impacts on skill in most cases shown in Fig. 14. The exception is the very dry Ranken catchment, where the benefits of the prior are equivocal. The prior removes the base case's negative skills in the Ranken catchment in JanuaryMarch, but also introduces negative skill in the drier months of June, August and December. We note that, on balance, this may have practical benefits: in another study (Turner et al., 2017) we show that FoGSS forecasts can benefit reservoir operations in cases where forecasts are not skilful in very dry months but positively or neutrally skilful at other times of the year. This is because the dry months contribute little to the annual inflow volume, so small positive bias in dry months (the cause of negative skill) does not have a strong influence on the value of forecasts. Conversely, a strong prior is responsible for removing negative skill in August in the Herbert catchment, and also removes the strongly negative skills in the Eppalock catchment in January-April. At the same time, the prior has little effect on the good performance of the base case in the Fitzroy, Ringarooma and Goobarragandra catchments.

We reiterate that the prior does not correct reliability problems in dry catchments, with PIT plots giving almost identical results to the base case (not shown for brevity). To mitigate the inherent tendency of the FoGSS error model to underestimate the occurrence of zero flows, we need to change its fundamental function. One approach for doing this would be to censor both simulations and observations in the MLE, and carry this approach through to generating forecasts. This would effectively change the assumption of a symmetrical error distribution about forecasts of zero, and offset the error distribution to increase the incidence of zeros. We will explore this approach in future research.

\section{Summary}

We assess a new seasonal streamflow forecasting system called forecast guided stochastic scenarios (FoGSS) for continent-wide application in Australia. FoGSS uses post-processed climate model forecasts to force a monthly rainfall-runoff model, and applies a staged error model to quantify and propagate hydrological model uncertainty. FoGSS is intended to provide a skilful alternative to resampled inflows for water agencies to use in operational planning: it is designed to extract skill from climate and catchment conditions, to produce unbiased and reliable ensemble predictions to 12-month forecast horizons, and to produce "coherent" forecasts when skill is not available - that is, forecasts that are similarly skilful to climatology.

FoGSS is assessed on 63 Australian catchments, of which 21 are ephemeral rivers. FoGSS performs well in all but the driest catchments. Skill is generally positive at shorter lead times in both perennial and ephemeral catchments, and transitions to neutral (near-zero) skill with respect to climatology at longer lead times. Forecast ensembles are generally reliable. However, in very dry catchments forecasts can be strongly negatively skilful and biased, in many cases because the ensembles are not reliable.

We conduct three experiments to establish whether components of the FoGSS system can be improved.

1. We use historical rainfall forcings - similar to ESP forecasts - to assess the contribution of forecast rainfall forcings to forecast skill.

2. We assess three monthly rainfall-runoff models (Wapaba, GR2M, and ABCD).

3. We use a Bayesian prior in our parameter estimation procedure to encourage the FoGSS error model to return climatology forecasts in months where the hydrological model performs poorly.

Historical rainfall forcings sometimes improve forecasts (largely in very dry catchments) by reducing bias. However, this comes at the cost of including useful information in rainfall forecasts, information that we show can accumulate over multiple lead times. On balance we believe the inclusion of seasonal rainfall forecasts in the FoGSS system is beneficial.

Wapaba and GR2M clearly outperform the ABCD rainfall-runoff model, and GR2M performs slightly better than Wapaba in ephemeral catchments. However, the advantages of the GR2M model are overshadowed by the use of the Bayesian prior. The prior reduces the instances of negative forecast skill and reduces bias in ephemeral catchments, and has little effect on performance in perennial catchments. The use of the prior does not, however, result in reliable forecast ensembles in catchments where zero flows occur more than half the time. We point to future research that could improve reliability in these very dry catchments.

Data availability. Rainfall data in this study are taken from the Australian Water Availability Project (AWAP), and are available at http://www.bom.gov.au/jsp/awap/. Potential evaporation data are also taken from AWAP: http://www.csiro.au/awap/. Streamflow 
gauge data used in this study are available through http://www.bom. gov.au/waterdata/. 


\section{Appendix A}

Table A1. List of catchments.

\begin{tabular}{|c|c|c|c|c|c|c|c|c|}
\hline Gauge mame & Gauge number & State $^{\mathrm{a}}$ & $\begin{array}{l}\text { Perennial/ } \\
\text { ephemeral }\end{array}$ & $\begin{array}{r}\text { Zero } \\
\text { flows }(\%)\end{array}$ & $\begin{array}{r}\text { Area } \\
\left(\mathrm{km}^{2}\right)\end{array}$ & Lon & Lat & $\begin{array}{l}\text { Missing } \\
\text { data (\%) }\end{array}$ \\
\hline Cotter River above Gingera & 410730 & ACT & Perennial & 0.0 & 130 & 148.82 & -35.59 & 1.2 \\
\hline Abercrombie River above Hadley No. 2 & 412066 & NSW & Perennial & 1.8 & 1631 & 149.6 & -34.11 & 2.7 \\
\hline Burrinjuck Dam inflows & Inflows site & NSW & Perennial & 0.0 & 10310 & 148.58 & -35.00 & 0.0 \\
\hline Corang River at Hockeys & 215004 & NSW & Perennial & 0.9 & 166 & 150.03 & -35.15 & 4.2 \\
\hline Goobarragandra River above Lacmalac & 410057 & NSW & Perennial & 0.0 & 668 & 148.35 & -35.33 & 0.3 \\
\hline Goodradigbee River above Wee Jasper (Kashmir) & 410024 & NSW & Perennial & 0.0 & 990 & 148.69 & -35.17 & 10.1 \\
\hline Murray River above Biggara & 401012 & NSW & Perennial & 0.0 & 1257 & 148.05 & -36.32 & 3.9 \\
\hline Nowendoc River above Rocks Crossing & 208005 & NSW & Perennial & 0.0 & 1893 & 152.08 & -31.78 & 1.8 \\
\hline Paroo River at Willarra Crossing & 424002 & NSW & Ephemeral & 19.9 & 35239 & 144.46 & -29.24 & 0.0 \\
\hline Wollomombi River above Coninside & 206014 & NSW & Perennial & 0.0 & 377 & 152.03 & -30.48 & 3.0 \\
\hline Daly River at Mount Nancar & G8140040 & NT & Perennial & 0.0 & 47100 & 130.74 & -13.83 & 4.8 \\
\hline Hugh River at South Road Crossing & G0050115 & NT & Ephemeral & 32.3 & 3140 & 133.43 & -24.35 & 4.2 \\
\hline Katherine River at Railway Bridge & G8140001 & NT & Perennial & 0.0 & 8640 & 132.26 & -14.46 & 3.3 \\
\hline Ranken River at Soudan Homestead & G0010005 & NT & Ephemeral & 72.4 & 4360 & 137.02 & -20.05 & 8.3 \\
\hline Roper River at Red Rock & G9030250 & NT & Perennial & 0.0 & 47400 & 134.42 & -14.70 & 14.6 \\
\hline South Alligator River at El Sherana & G8200045 & NT & Perennial & 0.0 & 1300 & 132.52 & -13.53 & 7.7 \\
\hline West Alligator River at Upstream Arnhem Highway & G8190001 & NT & Perennial & 0.0 & 316 & 132.17 & -12.79 & 3.9 \\
\hline Barron River above Picnic Crossing & $110003 \mathrm{~A}$ & QLD & Perennial & 0.0 & 239 & 145.54 & -17.26 & 0.0 \\
\hline Burdekin River above Sellheim & 120002 & QLD & Perennial & 0.6 & 36230 & 146.43 & -20.01 & 7.1 \\
\hline Coen River above Coen Racecourse & 922101B & QLD & Ephemeral & 5.1 & 170 & 143.2 & -13.94 & 6.0 \\
\hline Diamantina River at Birdsville & A0020101 & QLD & Ephemeral & 26.8 & 119034 & 139.37 & -25.91 & 3.3 \\
\hline Dulhunty River at Dougs Pad & $926002 \mathrm{~A}$ & QLD & Perennial & 2.3 & 332 & 142.42 & -11.83 & 8.0 \\
\hline Herbert River above Abergowrie & 116006B & QLD & Perennial & 0.0 & 7486 & 145.92 & -18.49 & 0.0 \\
\hline Namoi River above North Cuerindi & 419005 & QLD & Perennial & 0.0 & 2532 & 150.78 & -30.68 & 1.5 \\
\hline Nogoa River at Craigmore & 130209A & QLD & Ephemeral & 21.3 & 13876 & 147.76 & -23.88 & 13.4 \\
\hline Richmond River above Wiangaree & 203005 & QLD & Perennial & 0.0 & 712 & 152.97 & -28.51 & 0.6 \\
\hline Stuart River at Proston Rifle Range & $136304 \mathrm{~A}$ & QLD & Ephemeral & 16.7 & 1546 & 151.55 & -26.18 & 41.1 \\
\hline Stanley River above Peachester & 143303A & QLD & Perennial & 0.0 & 102 & 152.84 & -26.84 & 0.6 \\
\hline Cooper Creek at Cullyamurra Water Hole & A0030501 & SA & Ephemeral & 20.2 & 232846 & 140.84 & -27.7 & 0.0 \\
\hline Myponga US Dam and Road Bridge & A5020502 & SA & Perennial & 0.3 & 71 & 138.48 & -35.38 & 4.5 \\
\hline North Para River at Penrice & A5050517 & SA & Ephemeral & 11.1 & 121 & 139.06 & -34.46 & 3.3 \\
\hline Davey River above D/S Crossing Rv & 473 & TAS & Perennial & 0.0 & 698 & 145.95 & -43.14 & 0.9 \\
\hline Florentine above Derwent & 304040 & TAS & Perennial & 0.0 & 445 & 146.5 & -42.44 & 0.0 \\
\hline Hellyer River above Guilford Junction & 61 & TAS & Perennial & 0.0 & 101 & 145.67 & -41.42 & 0.3 \\
\hline Leven River at Bannons Bridge & 314207 & TAS & Perennial & 0.0 & 499 & 146.09 & -41.25 & 1.8 \\
\hline North Esk River at Ballroom & 318076 & TAS & Perennial & 0.0 & 363 & 147.38 & -41.49 & 0.9 \\
\hline Ringarooma River at Moorina Bridge & 30 & TAS & Perennial & 0.0 & 517 & 147.87 & -41.13 & 8.0 \\
\hline Swan River at the Grange & 302200 & TAS & Perennial & 0.0 & 448 & 148.08 & -42.05 & 7.4 \\
\hline Avoca River at Amphitheatre & 408202 & VIC & Ephemeral & 9.5 & 83 & 143.4 & -37.18 & 0.0 \\
\hline Lake Eildon & Inflows site & VIC & Perennial & 0.0 & 3877 & 145.97 & -37.16 & 0.0 \\
\hline Lake Eppalock & Inflows site & VIC & Ephemeral & 25.6 & 1749 & 144.56 & -36.88 & 0.0 \\
\hline Goulburn River above Dohertys & 405219 & VIC & Perennial & 0.0 & 700 & 146.13 & -37.33 & 4.5 \\
\hline Grace Burn Creek & Inflows site & VIC & Perennial & 0.0 & 25 & 145.55 & -37.64 & 0.0 \\
\hline Lake Hume & Inflows site & VIC & Perennial & 1.5 & 11754 & 147.15 & -36.08 & 0.0 \\
\hline Mosquito Creek above Struan & A2390519 & VIC & Ephemeral & 10.7 & 1249 & 140.77 & -37.09 & 0.0 \\
\hline Mitta Mitta River above Hinnomunjie & 401203 & VIC & Perennial & 0.0 & 1518 & 147.61 & -36.95 & 4.5 \\
\hline O’Shannassy Reservoir & Inflows site & VIC & Perennial & 0.0 & 127 & 145.81 & -37.68 & 0.0 \\
\hline Ovens inflows & Inflows site & VIC & Perennial & 0.0 & 7515 & 146.33 & -36.36 & 0.0 \\
\hline Tanjil Junction inflows & 85266 & VIC & Perennial & 0.0 & 289 & 146.19 & -37.98 & 0.0 \\
\hline Thomson Reservoir & Inflows site & VIC & Perennial & 0.0 & 487 & 146.37 & -37.79 & 0.0 \\
\hline Tambo River above Swifts Creek & 223202 & VIC & Perennial & 0.0 & 899 & 147.72 & -37.26 & 3.9 \\
\hline Upper Yarra Reservoir & Inflows site & VIC & Perennial & 0.0 & 337 & 145.92 & -37.68 & 0.0 \\
\hline Watts River inflows & Inflows Site & VIC & Perennial & 0.0 & 104 & 145.55 & -37.64 & 0.0 \\
\hline Darkin River at Pine Plantation & 616002 & WA & Ephemeral & 50.8 & 665 & 116.29 & -32.07 & 0.9 \\
\hline Denmark River at Mt. Lindesay & 603136 & WA & Perennial & 5.1 & 502 & 117.31 & -34.87 & 0.0 \\
\hline Deep River above Teds Pool & 606001 & WA & Ephemeral & 17.0 & 468 & 116.62 & -34.77 & 0.0 \\
\hline Fitzroy River at Fitzroy Crossing Br & 802055 & WA & Ephemeral & 4.2 & 46133 & 125.58 & -18.21 & 0.3 \\
\hline Gascoyne River at Nine Mile Bridge & 704139 & WA & Ephemeral & 60.1 & 74432 & 113.77 & -24.83 & 0.0 \\
\hline Harvey River above Dingo Road & 613002 & WA & Perennial & 0.6 & 148 & 116.04 & -33.09 & 2.4 \\
\hline Marillana Creek at Flat Rocks & 708001 & WA & Ephemeral & 29.8 & 1370 & 118.97 & -22.72 & 0.0 \\
\hline Ord River at Old Ord Homestead & 809316 & WA & Ephemeral & 26.2 & 19513 & 128.85 & -17.37 & 3.3 \\
\hline Serpentine Reservoir & Inflows site & WA & Ephemeral & 7.1 & 664 & 116.10 & -32.4 & 0.0 \\
\hline Young River at Neds Corner & 601001 & WA & Ephemeral & 42.6 & 1893 & 121.14 & -33.71 & 0.0 \\
\hline
\end{tabular}

Victoria: WA: Western Australia 


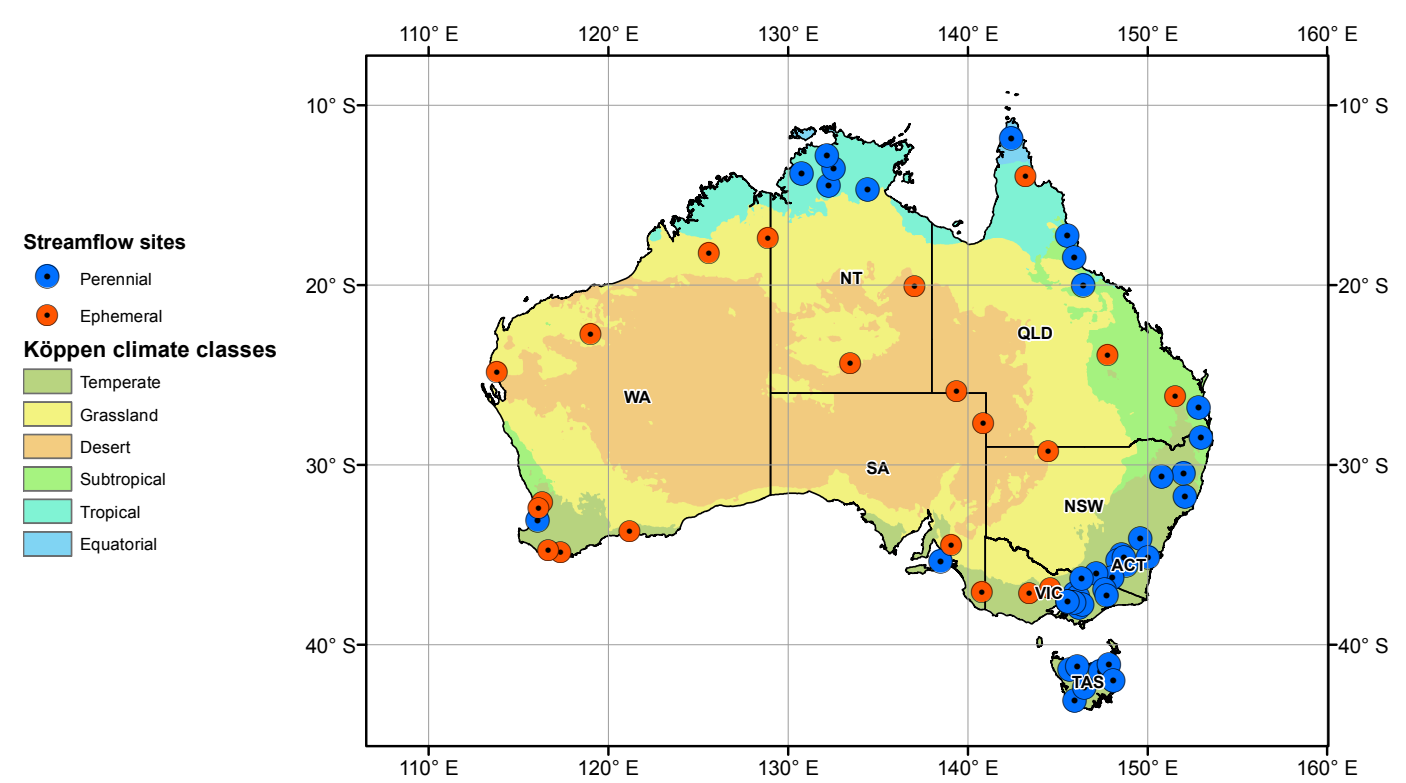

Figure A1. Distribution of gauge/inflow sites showing ephemeral/perennial streams. 


\section{Appendix B}

\begin{tabular}{|c|c|c|}
\hline $\begin{array}{l}\text { Surface } S_{\max } \\
\text { store } \\
\text { States } \\
S \text { and } G \text { are store states } \\
\alpha_{I} \quad \text { and } \alpha_{2} \quad \text { control catchment water } \\
\text { consumption, partitioning water into the } \\
\text { surface store, evaporation and catchment } \\
\text { yield } \\
S_{\text {max }} \text { controls the size of the surface store } \\
\beta \text { partitions catchment yield between direct } \\
\text { runoff and recharge to groundwater } \\
K \text { controls the rate of discharge from } \\
\text { groundwater }\end{array}$ & $\begin{array}{l}\text { Suface } \\
\text { store }\end{array}$ & $\begin{array}{l}\text { Production } \\
\text { store }\end{array}$ \\
\hline
\end{tabular}

Figure B1. Hydrological model structures and parameters. 
Appendix C: Posterior density used for estimation of Stage 2 parameters

We assume that residuals are normally distributed. Because parameters in Eq. (2) vary by month, $i=1,2, \ldots$, $12=\operatorname{month}(t)$, it follows that the residual distribution also varies by month:

$z_{\mathrm{O}}(t)=z_{2}(t)+\varepsilon_{2}(i)$,

$\varepsilon_{2}(i) \sim N\left(0, \sigma_{2}^{2}(i)\right)$.

The Stage 2 parameters to be estimated (from Eqs. 2 and C1) are denoted as

$\theta_{2}(i)=\left\{d(i), \mu(i), \sigma_{2}(i)\right\}$

We maximize the posterior density

$p\left(q_{\mathrm{o}}(t) \mid \theta_{2}(i), q_{1}(t)\right) \propto p(d) \prod_{t \in T_{i}} J_{q \rightarrow z} N\left(z_{\mathrm{o}}(t) \mid z_{2}(t), \sigma_{2}(i)\right)$, where $q_{1}$ is the simulation produced with Stage 1, the Jacobian (from the log-sinh transformation), $J_{z \rightarrow q}$, is given by

$J_{z \rightarrow q}=\frac{1}{\tanh \left(a+b q_{\mathrm{o}}(t)\right)}$

and $p(d)$ is the prior on the $d$ parameter (Sect. 4.4),

$p(d)=d \sim N\left(0, \sigma_{d}^{2}\right)$.

If $q_{\mathrm{o}}(t)=0$, then the likelihood term $J_{q \rightarrow z} N\left(z_{\mathrm{O}}(t) \mid z_{2}(t), \sigma_{2}(i)\right)$ in Eq. (C3) is substituted with the normal cumulative probability $\Phi\left(\frac{z_{\mathrm{c}}-z_{2}(t)}{\sigma_{2}(i)}\right)$, where $z_{\mathrm{c}}=\mathrm{TF}(0)$ is the $\log$-sinh transformed value of zero (see Eq. 1). 
Competing interests. The authors declare that they have no conflict of interest.

Special issue statement. This article is part of the special issue "Sub-seasonal to seasonal hydrological forecasting". It is a result of the HEPEX workshop on seasonal hydrological forecasting, Norrköping, Sweden, 21-23 September 2015.

Acknowledgements. This research has been supported by the Water Information Research and Development Alliance (WIRADA) between the Bureau of Meteorology and CSIRO Land \& Water. Thanks to Senlin Zhou, Julien Lerat, Paul Feikema and Daehyok Shin (all Bureau of Meteorology) for supplying data and for fruitful discussions on the development of FoGSS. Thanks to two anonymous reviewers for constructive and thorough reviews, and to Maria-Helena Ramos for editing the manuscript.

Edited by: Maria-Helena Ramos

Reviewed by: two anonymous referees

\section{References}

Alley, W. M.: On the Treatment of Evapotranspiration, Soil Moisture Accounting, and Aquifer Recharge in Monthly Water Balance Models, Water Resour. Res., 20, 1137-1149, https://doi.org/10.1029/WR020i008p01137, 1984.

Australian Government, Bureau of Meteorology: Rainfall, Australian Water Availability Project, available at: http://www.bom. gov.au/jsp/awap/, last access: 29 November 2017.

Australian Government, Bureau of Meteorology: Streamflow gauge records, available at: http://www.bom.gov.au/waterdata/, last access: 29 November 2017.

Beckers, J. V. L., Weerts, A. H., Tijdeman, E., and Welles, E.: ENSO-conditioned weather resampling method for seasonal ensemble streamflow prediction, Hydrol. Earth Syst. Sci., 20, 3277-3287, https://doi.org/10.5194/hess-20-3277-2016, 2016.

Bell, V. A., Davies, H. N., Kay, A. L., Brookshaw, A., and Scaife, A. A.: A national-scale seasonal hydrological forecast system: development and evaluation over Britain, Hydrol. Earth Syst. Sci., 21, 4681-4691, https://doi.org/10.5194/hess-21-4681-2017, 2017.

Bennett, J. C., Wang, Q. J., Li, M., Robertson, D. E., and Schepen, A.: Reliable long-range ensemble streamflow forecasts: Combining calibrated climate forecasts with a conceptual runoff model and a staged error model, Water Resour. Res., 52, 8238-8259, https://doi.org/10.1002/2016wr019193, 2016.

Candogan Yossef, N., van Beek, R., Weerts, A., Winsemius, H., and Bierkens, M. F. P.: Skill of a global forecasting system in seasonal ensemble streamflow prediction, Hydrol. Earth Syst. Sci., 21, 4103-4114, https://doi.org/10.5194/hess-21-4103-2017, 2017.

Clark, M. P., Gangopadhyay, S., Hay, L., Rajagopalan, B., and Wilby, R.: The Schaake shuffle: a method for reconstructing space-time variability in forecasted precipitation and temperature fields, J. Hy- drometeorol., $\quad 5, \quad 243-262, \quad$ https://doi.org/10.1175/15257541(2004)005<0243:TSSAMF>2.0.CO;2, 2004.

Crochemore, L., Ramos, M.-H., and Pappenberger, F.: Bias correcting precipitation forecasts to improve the skill of seasonal streamflow forecasts, Hydrol. Earth Syst. Sci., 20, 3601-3618, https://doi.org/10.5194/hess-20-3601-2016, 2016.

CSIRO: Potential evaporation, available at: http://www.csiro.au/ awap/, last access: 29 November 2017.

Day, G. N.: Extended streamflow forecasting using NWSRFS, J. Water Resour. Plann. Manag., 111, 157-170, https://doi.org/10.1061/(ASCE)0733-9496(1985)111:2(157), 1985.

Fundel, F., Jörg-Hess, S., and Zappa, M.: Monthly hydrometeorological ensemble prediction of streamflow droughts and corresponding drought indices, Hydrol. Earth Syst. Sci., 17, 395-407, https://doi.org/10.5194/hess-17-395-2013, 2013.

Gneiting, T. and Katzfuss, M.: Probabilistic forecasting, Annu. Rev. Stat. Appl., 1, 125-151, https://doi.org/10.1146/annurevstatistics-062713-085831, 2014.

Greuell, W., Franssen, W. H. P., Biemans, H., and Hutjes, R. W. A.: Seasonal streamflow forecasts for Europe - I. Hindcast verification with pseudo- and real observations, Hydrol. Earth Syst. Sci. Discuss., https://doi.org/10.5194/hess-2016-603, in review, 2016.

Hawthorne, S., Wang, Q. J., Schepen, A., and Robertson, D. E.: Effective use of GCM outputs for forecasting monthly rainfalls to long lead times, Water Resour. Res., 49, 5427-5436, https://doi.org/10.1002/wrcr.20453, 2013.

Hudson, D., Marshall, A. G., Yin, Y., Alves, O., and Hendon, H. H.: Improving intraseasonal prediction with a new ensemble generation strategy, Mon. Weather Rev., 141, 4429-4449, https://doi.org/10.1175/mwr-d-13-00059.1, 2013.

Jones, D. A., Wang, W., and Fawcett, R.: High-quality spatial climate data-sets for Australia, Aust. Meteorol. Ocean., 58, 233248, 2009.

Li, M., Wang, Q. J., and Bennett, J.: Accounting for seasonal dependence in hydrological model errors and prediction uncertainty, Water Resour. Res., 49, 5913-5929, https://doi.org/10.1002/wrcr.20445, 2013.

Li, M., Wang, Q. J., Bennett, J. C., and Robertson, D. E.: A strategy to overcome adverse effects of autoregressive updating of streamflow forecasts, Hydrol. Earth Syst. Sci., 19, 1-15, https://doi.org/10.5194/hess-19-1-2015, 2015.

Marshall, A. G., Hudson, D., Wheeler, M. C., Alves, O., Hendon, H. H., Pook, M. J., and Risbey, J. S.: Intra-seasonal drivers of extreme heat over Australia in observations and POAMA-2, Clim. Dynam., 43, 1915-1937, https://doi.org/10.1007/s00382013-2016-1, 2014.

Meißner, D., Klein, B., and Ionita, M.: Development of a monthly to seasonal forecast framework tailored to inland waterway transport in Central Europe, Hydrol. Earth Syst. Sci. Discuss., https://doi.org/10.5194/hess-2017-293, in review, 2017.

Mouelhi, S., Michel, C., Perrin, C., and Andréassian, V.: Stepwise development of a two-parameter monthly water balance model, J. Hydrol., 318, 200-214, https://doi.org/10.1016/j.jhydrol.2005.06.014, 2006.

Peng, Z., Wang, Q. J., Bennett, J. C., Schepen, A., Pappenberger, F., Pokhrel, P., and Wang, Z.: Statistical calibration and bridging of ECMWF System4 outputs for forecasting seasonal precip- 
itation over China, J. Geophys. Res.-Atmos., 119, 7116-7135, https://doi.org/10.1002/2013JD021162, 2014.

Raupach, M. R., Briggs, P. R., Haverd, V., King, E. A., Paget, M., and Trudinger, C. M.: Australian Water Availability Project (AWAP), final report for Phase 3, CSIRO Marine and Atmospheric Research, Canberra, Australia, 67 p., 2008.

Renard, B., Kavetski, D., Kuczera, G., Thyer, M., and Franks, S. W.: Understanding predictive uncertainty in hydrologic modeling: The challenge of identifying input and structural errors, Water Resour. Res., 46, W05521, https://doi.org/10.1029/2009wr008328, 2010.

Schepen, A. and Wang, Q.: Ensemble forecasts of monthly catchment rainfall out to long lead times by post-processing coupled general circulation model output, J. Hydrol., 519, 2920-2931, https://doi.org/10.1016/j.jhydrol.2014.03.017, 2014.

Schepen, A., Wang, Q. J., and Robertson, D. E.: Combining the strengths of statistical and dynamical modeling approaches for forecasting Australian seasonal rainfall, J. Geophys. Res., 117, D20107, https://doi.org/10.1029/2012JD018011, 2012.

Schepen, A., Wang, Q. J., and Robertson, D. E.: Seasonal forecasts of Australian rainfall through calibration and bridging of coupled GCM outputs, Mon. Weather Rev., 142, 1758-1770, https://doi.org/10.1175/mwr-d-13-00248.1, 2014.

Schepen, A., Wang, Q. J., and Robertson, D. E.: Application to postprocessing of meteorological seasonal forecasting, in: Handbook of hydrometeorological ensemble forecasting, 1 ed., edited by: Duan, Q., Pappenberger, F., Thielen, J., Wood, A., Cloke, H. L., and Schaake, J. C., Springer-Verlag Berlin Heidelberg, 1-29, 2016.

Thomas, H. A.: Improved methods for national water assessment, Harvard Water Resources Group, 1981.

Turner, S. W. D., Bennett, J. C., Robertson, D. E., and Galelli, S.: Complex relationship between seasonal streamflow forecast skill and value in reservoir operations, Hydrol. Earth Syst. Sci., 21, 4841-4859, https://doi.org/10.5194/hess-21-4841-2017, 2017.

Wang, Q. J. and Robertson, D. E.: Multisite probabilistic forecasting of seasonal flows for streams with zero value occurrences, Water Resour. Res., 47, W02546, https://doi.org/10.1029/2010WR009333, 2011.
Wang, Q. J., Pagano, T. C., Zhou, S. L., Hapuarachchi, H. A. P., Zhang, L., and Robertson, D. E.: Monthly versus daily water balance models in simulating monthly runoff, J. Hydrol., 404, 166-175, https://doi.org/10.1016/j.jhydrol.2011.04.027, 2011.

Wang, Q. J., Schepen, A., and Robertson, D. E.: Merging seasonal rainfall forecasts from multiple statistical models through Bayesian model averaging, J. Climate, 25, 5524-5537, https://doi.org/10.1175/JCLI-D-11-00386.1, 2012a.

Wang, Q. J., Shrestha, D. L., Robertson, D. E., and Pokhrel, P.: A $\log$-sinh transformation for data normalization and variance stabilization, Water Resour. Res., 48, W05514, https://doi.org/10.1029/2011WR010973, 2012b.

Wood, A. W. and Lettenmaier, D. P.: An ensemble approach for attribution of hydrologic prediction uncertainty, Geophys. Res. Lett., 35, L14401, https://doi.org/10.1029/2008g1034648, 2008.

Wood, A. W. and Schaake, J. C.: Correcting Errors in Streamflow Forecast Ensemble Mean and Spread, J. Hydrometeorol., 9, 132 148, https://doi.org/10.1175/2007jhm862.1, 2008.

Yuan, X.: An experimental seasonal hydrological forecasting system over the Yellow River basin - Part 2: The added value from climate forecast models, Hydrol. Earth Syst. Sci., 20, 24532466, https://doi.org/10.5194/hess-20-2453-2016, 2016.

Yuan, X., Wood, E. F., Chaney, N. W., Sheffield, J., Kam, J., Liang, M., and Guan, K.: Probabilistic Seasonal Forecasting of African Drought by Dynamical Models, J. Hydrometeorol., 14, 17061720, https://doi.org/10.1175/jhm-d-13-054.1, 2013.

Zhao, T., Schepen, A., and Wang, Q. J.: Ensemble forecasting of sub-seasonal to seasonal streamflow by a Bayesian joint probability modelling approach, J. Hydrol., 541, Part B, 839-849, https://doi.org/10.1016/j.jhydrol.2016.07.040, 2016.

Zhao, T., Bennett, J. C., Wang, Q. J., Schepen, A., Wood, A. W., Robertson, D. E., and Ramos, M.-H.: How suitable is quantile mapping for post-processing GCM precipitation forecasts?, J. Climate, 30, 3185-3196, https://doi.org/10.1175/jcli-d16-0652.1, 2017. 